\title{
A Regional Performance of Carotid Endarterectomy
}

\author{
by \\ John Hoi-Ying Wong (C)
}

A thesis submitted to the Faculty of Graduate Studies and Research in partial fulfillment of the requirements for the degree of Master of Science

in

Experimental Surgery

Department of Surgery

Edmonton, Alberta

Spring, 1997 
National Library of Canada

Acquisitions and Bibliographic Services

395 Wellington Street Ottawa ON KiA ONA Canada
Bibliothèque nationale du Canada

Acquisitions et services bibliographiques

395, ne Welfington Othawa ON KIA ON4 Canada
The author has granted a nonexclusive licence allowing the National Library of Canada to reproduce, loan, distribute or sell copies of his/her thesis by any means and in any form or format, making this thesis available to interested persons.

The author retains ownership of the copyright in his/her thesis. Neither the thesis nor substantial extracts from it may be printed or otherwise reproduced with the author's permission.
L'auteur a accordé une licence non exclusive permettant à la Bibliothèque nationale du Canada de reproduire, prêter, distribuer ou vendre des copies de sa thèse de quelque manière et sous quelque forme que ce soit pour mettre des exemplaires de cette thèse à la disposition des personnes intéressées.

L'auteur conserve la propriété du droit d'auteur qui protège sa thèse. Ni la thèse ni des extraits substantiels de celle-ci ne doivent être imprimés ou autrement reproduits sans son autorisation.

$0-612-21224-6$ 


\section{Dedication}

I dedicate this work to my dear and loving wife, Sheila, together with whom I will share a lifetime marked by exploration and discovery.

As well, this work is dedicated to my parents, Ben and Yin Mi Wong, whose humble beginnings and hard work have laid the secure foundations upon which I build my future. 


\section{Abstract}

Objective Guided by randomized studies evaluating carotid endarterectomy (CEA), we examined the appropriateness of CEAs performed in our city, and identified risk factors for operative complications. As well, we investigated the clinical significance of hemodynamic instability after CEA.

Methods We retrospectively reviewed 291 consecutive CEAs. Based upon randomized study results and angiographic remeasurements of carotid stenoses, indications for CEA were graded for appropriateness.

Results Surgical indications were uncertain in one-half, and inappropriate in one-fifth of cases, which was most commonly due to overestimated stenosis severity. Hemodynamic instability was common but only postoperative hypertension was associated with complications. Independent preoperative risk factors for neurological, cardiac, and hemodynamic complications were identified.

Conclusions Uniform angiographic measurement of carotid stenoses may reduce the rate of inappropriate CEAs. Our high complication rate in asymptomatic patients overshadowed any marginal surgical benefit. The frequency of postoperative hemodynamic problems suggests that patients should be closely monitored following CEA. 


\section{Acknowledgments}

The inspiration behind this work is from Dr. Max Findlay, under whose mentorship I have learned not only the skills of the scalpel but the equally important virtues of the scientific method. Only under his careful tutelage and guidance could this work have been realized.

I am indebted to Dr. Maria Suarez-Almazor for revealing to me answers to some of the mysteries that shroud statistics and epidemiology. Her review of this study was invaluable.

I also extend my gratitude towards the office personnel of the Division of Neurosurgery, and the staff of the Medical Records and Radiology departments of the various hospitals in Edmonton, Red Deer, and Grande Prairie, for their aid in locating nearly three hundred hospital charts and films. As well, my thanks go out to the staff at the Alberta Health Department for their careful review of the provincial healthcare databases. 


\section{Table of Contents}

Chapter 1: Introduction........................................................ 1

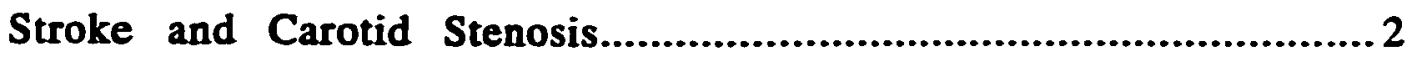

Management of Carotid Stenosis .............................................. 5

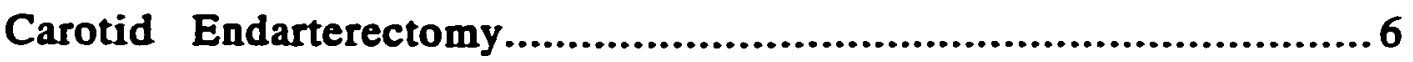

Symptomatic Patient Trials.......................................... 7

Asymptomatic Patient Trials ......................................... 9

Indications for Carotid Endarterectomy...............................................11

Bibliography .................................................................. 16

\section{Chapter 2t A Regional Performance of Carotid}

Endarterectomy............................................................. 24

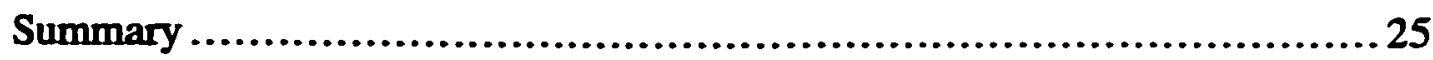

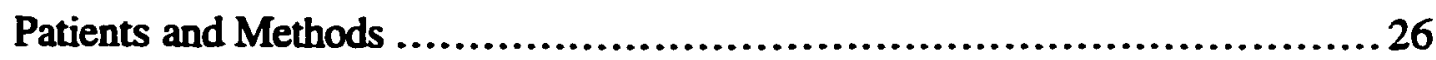

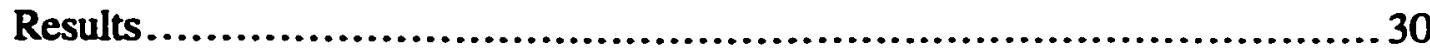

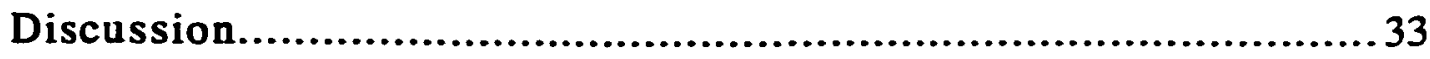

Appropriateness of Carotid Endarterectomy ............................ 33

Complications of Carotid Endarterectomy........................................37

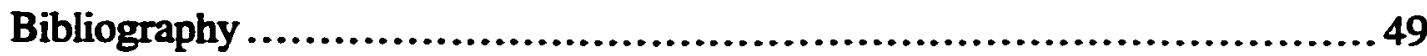

\section{Chapter 3: Memodynamic Instability After Carotid}

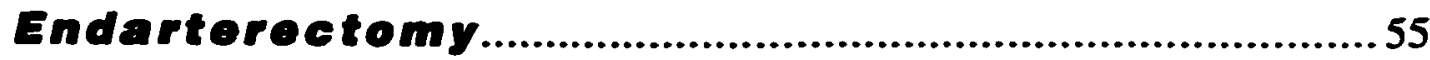

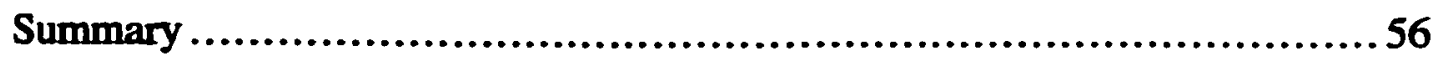

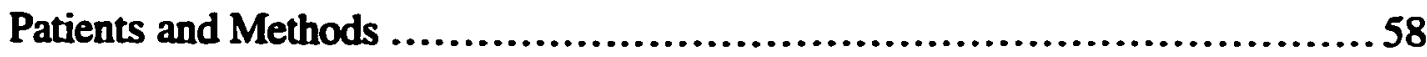

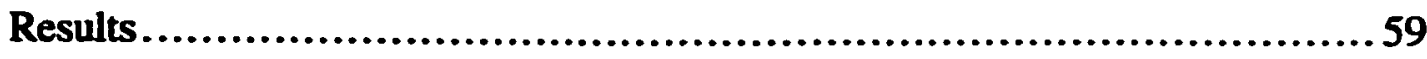

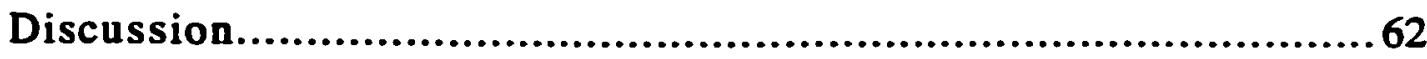

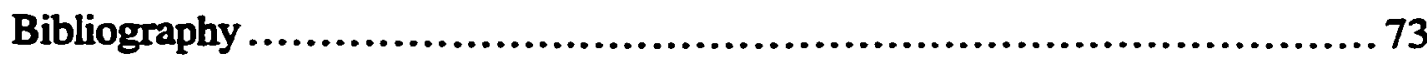

Chaptor 4: Conclusions......................................................... 77

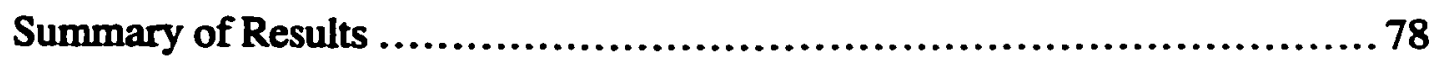

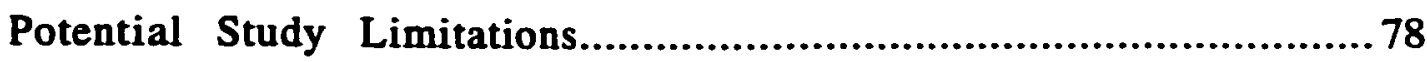

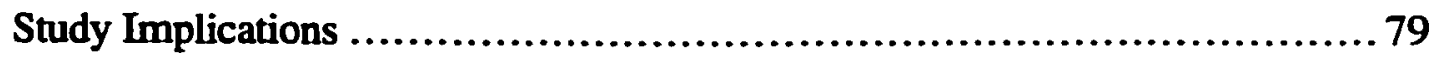




\section{List of Tables}

\section{Chapter 2}

Table 2-1. Selected characteristics of patient population. 40

Table 2-2A. Accuracy of preoperative angiography for symptomatic carotid stenoses

Table 2-2B. Accuracy of preoperative angiography for asymptomatic carotid stenoses

Table 2-3A. Accuracy of ultrasonography compared to NASCET angiography for carotid stenoses $\geq 50 \%$

Table 2-3B. Accuracy of uitrasonography compared to NASCET angiography for carotid stenoses $\geq 80 \%$

Table 2-4. Appropriateness of carotid endarterectomy 45

Table 2-5. Significant risk factors for postoperative complications by univariate analysis.

Table 2-6. Independent preoperative risk factors for postoperative complications by multiple logistic regression analysis

Table 2-7. Summary of selected randomized controlled trial results 48

\section{Chapter 3}

Table 3-1. Frequency of selected patient characteristics .......................68

Table 3-2. Hemodynamic instability ..........................................69

Table 3-3. Potential risk factors for postoperative hypertension by univariate analysis.

Table 3-4. Independent preoperative risk factors for postoperative hypertension by multivariate analysis 


\section{List of Abbreviations}

ACAS

Asymp

BP

bpm

CABG

CAD

CASANOVA

CEA

CHF

CI

COPD

CT

ECST

ICA

ICU

Ipsi

K

MI

mm Hg

NASCET

NNT

OR

SBP

Symp

TIA

TMB

VA
Asymptomatic Carotid Atherosclerosis Study

Asymptomatic

Blood Pressure

Beats Per Minute

Coronary Artery Bypass Grafting

Coronary Artery Disease

Carotid Artery Stenosis with Asymptomatic Narrowing;

Operation Versus Aspirin

Carotid Endarterectomy

Congestive Heart Failure

Confidence Interval

Chronic Obstructive Pulmonary Disease

Computed Tomography

European Carotid Stenosis Trial

Internal Carotid Artery

Intensive Care Unit

Ipsilateral

Kappa

Myocardial Infarction

Millimeters Mercury

North American Symptomatic Carotid Endarterectomy Trial

Number Needed to Treat

Odds Ratio

Systolic Blood Pressure

Symptomatic

Transient Ischemic Attack

Transient Monocular Blindness

Veterans Affairs 


\section{Chapter 1}

\section{INTRODUCTION}

An abridged version of this chapter has been accepted for publication. Wong JH, Findlay JM, How to prevent strokes. Canadian Journal of Continuing Medical Education. 1997;9 (In press). 


\section{Stroke and Carotid Stenosis}

Stroke is the third leading cause of mortality in Canada, accounting for about 14,000 deaths annually, ${ }^{\mathfrak{l}}$ and has a worldwide incidence of about 179 per 100000 per year. ${ }^{2}$ Even more sobering is the fact that stroke alone accounts for almost $10 \%$ of all patient days in Canadian hospitals ${ }^{l}$ and thus represents a significant burden on the Canadian healthcare system. About $70-80 \%$ of all strokes are ischemic, but the exact proportion of these which is secondary to thromboembolism has not been determined; in a series of 79 patients who underwent angiography after atherosclerotic cerebral infarction, it was found that $62 \%$ had occlusion or severe stenosis of the internal carotid artery. ${ }^{3}$

Carotid stenosis refers to narrowing of the internal carotid artery at the carotid bifurcation in the neck. In the vast majority of cases, it is due to the accumulation of atheromatous plaque at the bifurcation that results in a stenotic lesion. The lesion may reduce blood supply to the ipsilateral cerebral hemisphere that in combination with inadequate vertebral and contralateral carotid arterial collateral flow, results in focal hemodynamic insufficiency and cerebral ischemia. More commonly, stroke from carotid disease is the resuit of turbulent blood flow at the carotid bifurcation due to the local stenosis. This predisposes to the formation of thromboembolic material which passes distally into the retinal or cerebral circulation causing a transient ischemic attack (TIA) or permanent cerebral infarction. The carotid plaque may be ulcerated, which is detected angiographically in about one-third of patients undergoing carotid surgery, and associated with an increased risk of stroke. ${ }^{4}$ This risk is increased even more so if the patient has an ulcer in the presence of a critically stenosed vessel. Since previous studies have shown that angiography poorly predicts the presence of ulcers observed intraoperatively, ${ }^{5}$ ulceration severe enough to be seen on angiography may reflect morphological changes of the carotid plaque that increase the risk of clinical thromboembolism, perhaps as a result of increased turbulence or greater local thrombogenicity. 
Estimates of the prevalence of carotid stenosis in the general population have been based on the presumption that a carotid bruit is a marker for underlying stenosis. The Framingham study found bruits to occur in $4.6 \%$ of persons older than 43 years. ${ }^{6}$ However, prospective studies have also suggested that a carotid bruit is an indicator of generalized advanced atherosclerotic disease and in certain instances, may be a stronger predictor for future ischemic heart disease than for stroke. ${ }^{6-8}$ As well, a carotid bruit is an imperfect means of assessing ipsilateral stroke risk as many subsequent strokes occur outside of the vascular territory of the artery with bruit. 6

A patient with a history of TIA (strictly defined as a neurological deficit that resolves within 24 hours, but usually a deficit that lasts only several minutes) or stroke should raise the suspicion of thromboembolism, which most commonly occurs from the carotid bifurcation. Cerebral ischemia developing as a result of carotid stenosis, commonly manifests itself as symptoms of unilateral weakness or sensory change of the face, arm, or less commonly, leg. If the dominant hemisphere (usually left) is affected, speech difficulties or dysphasia may arise. Emboli to the retinal circulation may result in amaurosis fugax, which is temporary monocular blindness commonly described as a falling dark curtain that obscures vision in one eye only, or permanent visual loss due to retinal infarction. Frequently the diagnosis of carotid stenosis is not suspected until the patient has already suffered a stroke. However, the goal of secondary stroke prevention is still worthwhile if the neurological deficit is non-disabling and such patients should be aggressively managed to preserve remaining function.

Nonspecific neurological symptoms such as dizziness, syncope, or cognitive difficulties, are not typical manifestations of carotid thromboembolism. If such patients are subsequently found to have carotid stenosis, they should be considered asymptomatic from their carotid disease. Uncommonly, patients may be incidentally diagnosed with carotid stenosis if they are undergoing radiological investigations such as coronary or cerebral 
angiography for other medical reasons. These patients should also be considered as being asymptomatic if no prior history of ipsilateral cerebral or retinal ischemia is elicited.

The risk of future stroke from carotid stenosis is related to the symptom status of the patient. Patients with symptomatic carotid disease are at higher risk of stroke than those who are asymptomatic or than the general population: patients presenting with a TIA or amaurosis fugax have an aggregate annual risk of stroke of $3.7 \%$ and $2.2 \%$, respectively; those with asymptomatic carotid stenosis have a $1.3 \%$ annual stroke rate; and the general elderly population has a $0.6 \%$ risk of stroke per year. 9

The initial diagnostic work-up for suspected carotid stenosis relies upon noninvasive carotid artery testing. These investigations include direct tests that detect blood flow within the carotid artery, such as carotid ultrasonography, and indirect tests which measure the flow through collateral vessels, such as oculoplethysmography. It is the former, carotid ultrasonography, that is the mainstay of non-invasive diagnostic testing for carotid disease. It is important to note that the results of ultrasonography are dependent upon the operator and technique. Studies have shown that the sensitivity of ultrasonography can vary widely from $25-92 \%$ depending on the degree of vessel narrowing. ${ }^{10}$ As well, ultrasonography may mistakenly identify patients with critical preocclusive carotid disease as having a completely blocked artery. Because of these concerns, patients with significant carotid disease should undergo further imaging to more exactly quantify the degree of stenosis, especially prior to surgery.

Carotid or cerebral angiography is considered the diagnostic go!d standard for carotid stenosis. This procedure is performed by neuroradiologists in the hospital setting although many are now performed on an outpatient basis. ${ }^{11} \mathrm{~A}$ catheter is percutaneously introduced via the femoral artery, and the carotid and vertebral arteries are selectively injected with radiocontrast, thereby enabling precise definition of the carotid plaque, assessment of collateral cerebral blood flow, and identification of any intracranial vascular anomalies such as cerebral aneurysms or arteriovenous malformations. Although 
angiography is essential towards quantifying the degree of carotid stenosis, it is usually reserved for patients with significant stenoses identified on ultrasound as angiography is an invasive procedure associated with about a $4 \%$ risk of transient neurological deficit and a $1 \%$ risk of stroke. ${ }^{12}$ As a result of these concerns, computed tomographic angiography and magnetic resonance angiography are being developed as means of assessing the carotid bifurcation without the risks of conventional angiography. However, currently these modalities are of limited availability to most Canadian clinicians.

\section{Management of Carotid Stenosis}

The management of carotid stenosis begins with non-surgical therapy, namely risk factor modification and antiplatelet medication. Since carotid stenosis is a marker for diffuse atherosclerotic disease and ischemic heart disease is the most common cause of death following carotid endarterectomy (CEA), the importance of aggressively treating comorbid medical conditions and reducing risk factors such as smoking, cannot be overemphasized.

Aspirin has been commonly used in the treatment of cardiovascular and cerebrovascular disease. Its antithrombotic effects are mediated mostly by inhibition of thromboxane $A_{2}$, which is a factor responsible for platelet aggregation. A meta-analysis of several trials studying the efficacy of aspirin for secondary stroke prevention after TIA and stroke, found that aspirin reduced the risks of subsequent stroke by $21 \%$ and $26 \%$, respectively. ${ }^{13}$ However, the benefit of aspirin for primary stroke prevention (i.e. those patients without prior symptoms of cerebral or retinal ischemia) is uncertain; the risk of aspirin-related gastrointestinal hemorrhage and possibly hemorrhagic stroke in healthy individuals may off-set the benefit of aspirin in preventing cardiovascular and cerebrovascular disease. However, for those with atherosclerosis or at high risk of stroke, aspirin may be beneficial in conjunction with modification of risk factors in reducing the 
possibility of primary stroke. ${ }^{14}$ The most appropriate and effective dose of aspirin for treating cerebrovascular disease remains to be defined.

For those patients who are intolerant of aspirin or who continue to have TIAs while on aspirin, the antiplatelet agent ticlopidine is commonly substituted. Its efficacy has been demonstrated in a large comparative trial with aspirin using over 3000 patients with recent TIA or minor stroke, where ticlopidine reduced the incidence of stroke by $21 \%$ over 3 years. ${ }^{15}$ Widespread use of ticlopidine as a first-line agent has perhaps been limited by its higher cost relative to aspirin, its potential side effects including diarrhea, rash, and reversible neutropenia, and the need for periodic blood tests to monitor for toxicity, i.e. a white blood cell count every two weeks for three months.

\section{Carotid Endarterectomy}

Carotid endarterectomy, the surgical resection of atheromatous plaque from the bifurcation, has recently undergone a resurgence in popularity. Although the use of carotid surgery to treat cerebrovascular disease was first described in $1954,{ }^{16}$ it was not until nearly 40 years later that definitive evidence supporting CEA became available. Despite early problematic randomized trials that failed to demonstrate any efficacy of surgery for carotid stenosis, ${ }^{17,} 18$ CEA steadily rose in popularity, climbing from 15,000 to 107,000 operations during 1971 to 1985 in non-federal American hospitals, ${ }^{19}$ thereby becoming the third most common operation performed in the United States. However, a growing mood of pessimism overshadowed this operation as evidenced by a dramatic drop to 83,000 surgeries in $1986 .{ }^{19}$ Concerns were raised over the possible misuse of CEA as shown by Winslow and colleagues who found that almost one-third of CEAs were performed for inappropriate reasons in a population of 1302 Medicare patients who underwent surgery. 20 High operative complication rates were reported with some communities having stroke or death rates as high as $21 \%$ after CEA. ${ }^{21}$ As well, advances in non-surgical stroke treatment 
and risk-factor reduction, the growing recognition of the important role of anti-platelet agents, and the failure of extracranial to intracranial bypass grafting in secondary stroke prevention also helped galvanize interest in a scientific re-appraisal of CEA and contributed to the call for the establishment of randomized controlled trials studying CEA. ${ }^{22}$

\section{Symptomatic Patient Trials}

In an attempt to conclusively define the efficacy of CEA, several randomized controlled trials were initiated. In December 1987, randomization began for the North American Symptomatic Carotid Endarterectomy Trial (NASCET) ${ }^{23,24}$ which set out to evaluate the effect of CEA in conjunction with best medical therapy, compared with medical care alone, for patients symptomatic from carotid disease. ${ }^{25}$ Six hundred and fifty-nine patients were randomized, after suffering a previous ipsilateral hemispheric TIA, nondisabling stroke, or episode of temporary monocular blindness within the previous 120 days. Standard investigations included computed tomography (CT) of the brain, carotid angiography, and carotid duplex ultrasonography. Patients were stratified by their degree of carotid stenosis: 30 to 69 percent (moderate), and 70 to 99 percent (severe). This percentage stenosis was based upon angiographic comparison of the site of maximal luminal narrowing with the normal distal internal carotid artery. All patients received optimal medical treatment which included an anti-platelet regimen and control of modifiable medical risk factors and were monitored for the primary end point of stroke or death. Interim results were published in 1991 for the group with severe stenosis. In the surgical arm, an absolute risk reduction was found after 2 years of $11 \pm 3 \%$ for major or fatal ipsilateral stroke, and $17 \pm 4 \%$ for ipsilateral stroke. The efficacy of CEA was found to improve with worsening degrees of stenosis; there was an absolute risk reduction of $26 \pm 8 \%$ for ipsilateral stroke in patients with $90-99 \%$ stenosis, compared with $12 \pm 5 \%$ in patients with lesser stenoses of 70-79\%. The beneficial effect of CEA was inversely proportional to the operative complication rate; a high degree of surgical competence was required to achieve the low $2.1 \%$ perioperative risk of major stroke or death. The authors 
concluded that CEA had a clear beneficial effect in reducing stroke risk for select patients with severe $(\geq 70 \%)$ symptomatic carotid stenosis. With respect to patients with moderate (30-69\%) stenoses, NASCET recruitment continues presently.

Interim data from the European Carotid Surgery Trial (ECST), released at about the same time as that of NASCET, also supported the use of CEA in patients with symptomatic carotid disease. ${ }^{26}$ Seven hundred and seventy-eight patients with angiographic carotid stenoses of 70-99\% causing prior non-disabling ischemic stroke, TIA, or retinal infarction were randomized to optimal medical care with or without CEA, and followed for an average of 2.7 years. Stroke or death occurred within 30 days of surgery in $7.5 \%$ of patients. A surgical advantage was found in comparison to the medical group; there was a $5.0 \%$ absolute risk reduction for disabling or fatal stroke or surgical death, and a $7.3 \%$ absolute risk reduction for disabling or fatal ipsilateral ischemic stroke. In the same study, 374 patients with mild (0-29\%) carotid stenosis were similarly randomized, but there was no significant difference between the two groups in terms of stroke and there were no disabling or fatal strokes to be prevented in the medical group. Carotid endarterectomy was therefore recommended in patients with severe $(\geq 70 \%)$ but not mild $(<30 \%)$ carotid stenosis.

The smaller Veterans Affairs study, launched in 1988, was terminated prematurely due to the publication of the NASCET and ECST results. ${ }^{27}$ In this study, 189 men with greater than $50 \%$ carotid stenosis were randomized to medical care with or without CEA and followed for an average of 12 months for the combined primary outcome event of ipsilateral crescendo TIA or stroke, or death within 30 days of randomization. A significant surgical advantage was found: the risk of crescendo TIA, stroke, or perioperative death was $7.7 \%$ in the surgical group versus $19.4 \%$ in the non-surgical group, thus giving an absolute risk reduction of $11.7 \%$. The authors determined that CEA was beneficial in reducing the risk of cerebral ischemia in patients with high-grade symptomatic carotid stenosis. However, the clinical relevance of this study has been questioned due to the 
inclusion of crescendo TIA as a primary endpoint since crescendo TIA has not been definitively proven to herald impending cerebral infarction.

These aforementioned studies have demonstrated a marked beneficial effect of CEA on symptomatic carotid disease under select circumstances. Although the Veteran's Affairs study demonstrated surgical efficacy for carotid stenoses greater than $50 \%$, due to the smaller number of patients enrolled in this trial and its questioned primary endpoint, most authorities still consider $70 \%$ as the degree of carotid stenosis needed to justify surgery in the symptomatic patient. ${ }^{28}$ However, even this $70 \%$ stenosis "cut-off" point is not without controversy since NASCET and ECST differed in their methods of angiographic evaluation. Depending upon the manner of measurement used, it has been shown that the same angiogram yields differing values of carotid stenosis: $: 29,30$ a 70\% NASCET stenosis is equivalent to an $82 \%$ ECST narrowing. ${ }^{31}$

\section{Asymptomatic Patient Trials}

The utility of CEA for asymptomatic carotid stenosis has also been examined in a number of randomized controlled trials. Published in 1991, the CASANOVA (Carotid Artery Stenosis with Asymptomatic Narrowing; Operation Versus Aspirin) study, a randomized trial of 410 patients with asymptomatic carotid stenosis of $50-90 \%$ did not find CEA useful in preventing stroke or death when compared to medical treatment alone. ${ }^{32}$ However, this trial was limited by a complex study design that excluded patients with critical (>90\%) stenoses from study, whom current evidence suggests potentially gain the most from CEA. The Mayo Asymptomatic Carotid Endarterectomy study was prematurely terminated in 1990 after recruiting 158 patients, due to an excessive number of myocardial infarctions and TIAs in the surgical arm of the trial. ${ }^{33}$ These complications have been attributed to the lack of preoperative aspirin use; adjunctive aspirin therapy has since been shown to reduce stroke and prolong survival after CEA. ${ }^{34,35}$

The Asymptomatic Carotid Stenosis Veterans Administration Cooperative Study, published in January 1993, found CEA reduced the incidence of neurological events for 
those with asymptomatic carotid disease. ${ }^{36}$ Four hundred and forty-four men with angiographic asymptomatic carotid stenosis equal to or greater than $50 \%$ were randomly assigned to optimal medical treatment with or without CEA. The primary endpoint was the combined incidence of ipsilateral TIA, transient monocular blindness, or stroke. After a mean followup of almost four years, the incidence of combined neurological events was $8 \%$ in those who had surgery, versus $21 \%$ in those treated with medical therapy alone $(\mathrm{P}<0.001$, relative risk 0.38$)$. The 30 day stroke or death rate was $4.7 \%$ in the surgical group. Although the authors concluded that surgery reduced the risk of neurological events, critics have argued that TIA and amaurosis fugax are clinically less important than stroke and hence should not have been included in the definition of a primary endpoint. ${ }^{37}$ This study also failed to demonstrate a significant difference between the two patient groups in terms of stroke or death, possibly as a result of the limited number of patients enrolled.

The Asymptomatic Carotid Atherosclerosis Study (ACAS), first published in December 1994, supported CEA in reducing the risk of stroke and death for selected asymptomatic patients. ${ }^{38}$ One thousand six-hundred and sixty-two patients with asymptomatic carotid stenosis greater than or equal to $60 \%$ by ultrasonography or angiography (as measured by NASCET criteria) were randomized to optimal medical therapy with or without surgery. After a median of 2.7 years follow-up, it was found that those allocated to surgery had a relative-risk reduction of $53 \%$ for ipsilateral stroke (or any postoperative stroke or death), with an absolute risk reduction of 5.9\% projected over five years compared to the non-surgical group. The $\mathbf{3 0}$ day operative stroke or death rate was very low at only $2.3 \%$ by intention-to-treat analysis, and even lower at $1.5 \%$ if only those who underwent surgery were considered. No conclusions were reached regarding risk stratification based on severity of stenosis since some patients did not undergo angiography. The authors concluded that for those patients with $\geq 60 \%$ asymptomatic carotid stenosis, CEA was efficacious in reducing the risk of stroke or death. 
Although the ACAS trial has provided arguably the strongest evidence to date in favor of operation for asymptomatic carotid disease, this study has been the subject of intense scrutiny. Given that surgical benefit of CEA for symptomatic patients with moderate stenoses has yet to be demonstrated ${ }^{39}$ and given that the natural history of the asymptomatic carotid plaque is not especially dangerous, ${ }^{9,} 40$ doubts persist over the efficacy of CEA for asymptomatic patients. ${ }^{41}$ Although the ACAS data did show a significant reduction for stroke, results for other clinically important outcomes such as major stroke or death did not reach statistical significance ${ }^{42}$ and subgroup analysis did not reveal any surgical benefit for women. Also, the absolute risk reduction for future stroke afforded by CEA was only slightly more than $1 \%$ per year; to prevent one stroke in five years, about 17 patients require operation, and to prevent one stroke in two years, 67 patients need CEA. ${ }^{43}$ As well, its surprisingly low complication rate may be difficult to match in a routine community surgical practice. These observations suggest that although the results of ACAS are statistically significant, they may not be clinically relevant. Cautious clinicians are awaiting the results of future randomized trials investigating asymptomatic carotid stenosis such as the Asymptomatic Carotid Surgery Trial in Europe. $^{44}$

\section{Indications for Carotid Endarterectomy}

The designation of what is an appropriate surgical indication depends upon available established scientific knowledge. Prior assessments of surgical appropriateness were based upon subjective recommendations from expert panels. ${ }^{20 .} 45$ However, the recent randomized trials have afforded the opportunity to base determinations of appropriateness upon objective evidence and have offered guidelines as to which patients may benefit from carotid surgery. Extrapolating the favorable results of studies evaluating CEA outside the confines of the research setting into the general community require certain 
conditions to be met. Patients should be comparable to the study population, and diagnostic methods must be similar and accurate. As well, operative complication rates should not exceed those found in the randomized trials.

Essential parameters which help decide surgical appropriateness include the symptom status of the patient and the degree of angiographic stenosis of the carotid artery in question. Symptomatic patients with $\geq 70 \%$ stenosis on angiography clearly benefit from CEA as shown by two randomized trials; $; 4,26$ only six such patients need to undergo surgery to prevent a stroke or death within two years. Of importance is the fact that a standardized technique of angiographic measurement should be used (such as the method used in the NASCET study i.e. by comparing the greatest linear stenosis with the distal normal internal carotid artery diameter), since the severity of angiographic stenosis varies with the measurement method. As the NASCET trial has not yet reported on the status of symptomatic patients with less than $70 \%$ stenosis, this indication for CEA is currently considered uncertain. Carotid endarterectomy has not been shown to benefit patients with long-standing carotid occlusion.

The benefit of surgery for asymptomatic carotid stenosis is controversial. The only randomized controlled study to date showing efficacy of CEA in preventing stroke for asymptomatic patients is ACAS, the results of which require careful consideration. ${ }^{38}$ Because the benefit of CEA for asymptomatic stenoses $\geq 60 \%$ seems marginal and dependent upon a very low operative complication rate, this surgical indication may be considered uncertain.

Patients who have asymptomatic carotid stenoses less than $60 \%$ should not undergo CEA due to a lack of proven efficacy. Instead, these patients should have control of any modifiable risk factors for stroke. Periodic follow-up by ultrasound will identify patients with worsening carotid stenosis, thus making CEA possibly a more reasonable treatment option for asymptomatic carotid disease. Other factors that may make the asymptomatic patient a more appropriate surgical candidate are the presence of silent cerebral infarcts on 
CT scan of the brain, high-grade ( $>90 \%$ ) carotid stenosis, contralateral carotid occlusion, and plaque ulceration. The issue of whether silent cerebral infarction increases the risk of future stroke in those with carotid stenosis remains unsettled. Norris and Zhu previously compared the CT brain scans of patients with asymptomatic carotid stenosis, TIAs and carotid stenosis, and TIAs without carotid stenosis. ${ }^{46}$ They found silent cerebral infarction was most common in the group with TIAs and carotid stenosis, as it affected $47 \%$ of cases. As well, it was found that the more narrow the carotid artery, the greater the prevalence of silent cerebral infarction. However, all the observed infarcts were small (i.e. $<15 \mathrm{~mm}$ ) and not all infarcts were ipsilateral to the side of the carotid stenosis. Although they concluded that silent cerebral infarction may prove to be an indication for CEA, this conjecture has yet to be substantiated in a prospective study.

Other important aspects of surgical appropriateness are suggested by the patient inclusion and exclusion criteria in the NASCET study. ${ }^{24}$ Patients being considered for CEA should be medically stable, e.g. absence of lung, liver, or kidney failure, uncontrolled hypertension, diabetes mellitus, or unstable angina, have a reasonable life expectancy, have a surgically accessible carotid lesion, and should not have more severe atherosclerotic disease in the distal intracranial internal carotid artery. The NASCET study also excluded from study patients who were unstable. Neurologically unstable patients, i.e. those with neurological symptoms that are progressing or of recent onset, should only be considered for urgent surgery if their condition proves refractory to medical therapy such as anticoagulation. Patients with carotid stenosis, whether symptomatic or asymptomatic, who have uncontrolled medical illnesses such as labile hypertension, severe congestive heart failure, or recent myocardial infarction, should have surgery delayed until their condition is stabilized.

A low perioperative complication rate is essential if CEA is to benefit the patient. Ironically, although the goal of CEA is to prevent stroke, it is the main complication of the procedure. Surgery should only be carried out if the risk of operative complications, i.e. 
perioperative stroke or death, can be contained at acceptable levels. In situations where the natural history of carotid stenosis already yields a low risk of stroke as in the asymptomatic patient, the frequency of perioperative complications should be even more rare. Clinical practice guidelines from the American Heart Association have suggested that for symptomatic patients, the postoperative stroke or death rate should be less than $6 \%$, and for asymptomatic patients, the rate should be less than $3 \% .47$

Several groups have previously described potential risk factors for surgical complications after CEA. ${ }^{48-53}$ In 1975, Sundt and colleagues determined that those with neurological risk factors, (i.e. progressing neurological deficit, neurological deficit of less than 24 hours duration, frequent daily TIAs, or neurological deficits secondary to multiple cerebral infarctions), were at highest risk for postoperative myocardial infarction and stroke. ${ }^{54}$ Although risk factors for cardiac complications have been less commonly studied in the literature, it is widely acknowledged that those undergoing CEA frequently harbor either occult or symptomatic cardiac disease. ${ }^{55-62}$ Through analysis of risk factors, the preoperative identification of high-risk patients may offer an opportunity to reduce complications, such as through correction of medical problems prior to surgery or postoperative monitoring of such patients in an intensive care unit.

In the past, CEA has been used as a measure of the appropriateness of health care services $^{20,63-65}$ but no studies have been published concerning the appropriateness of CEA since the release of the randomized clinical trial results. It remains to be seen whether current practice in the community is following the recommendations of these landmark studies. Since referral of patients with symptomatic carotid stenosis has been increasing, presumably due to dissemination of the favorable NASCET results, ${ }^{66}$ and since up to half of all CEAs may be being performed for asymptomatic disease, ${ }^{43}$ vigilance is needed to ensure that appropriate indications for CEA are being followed in the community to prevent overutilization and unnecessary operations. As well, the randomized clinical trials were conducted in centers selected for their proficiency in performing CEA, and yet most CEAs 
are performed in community hospitals that are not typically subject to such close scrutiny. Authorities have proposed that only those medical centers able to demonstrate surgical complication rates comparable to those of the randomized trials, preferably by independent audit, would be able to justify the use of CEA especially for patients with asymptomatic carotid disease. ${ }^{47,67}$ In light of the operative standards of care established by the multicenter clinical trials, the performance of this procedure on the community level deserves equally close scientific attention to ensure that the goal of stroke prevention is being achieved in a safe and acceptable manner. 


\section{Bibliography}

1. Heart and Stroke Foundation of Canada: Cardiovascular disease in Canada. Ottawa, Canada, 1993.

2. Mohr JP, Lee SH: Carotid disease, in Carter PL, Spetzler RF, Hamilton MG (eds): Neurovascular surgery. New York: McGraw-Hill, 1995, pp 263-279.

3. Timsit SG, Sacco RL, Mohr JP, Foulkes MA, Tatemichi TK, Wolf PA, Price TR, Hier DB. Early clinical differentiation of cerebral infarction from severe atherosclerotic stenosis and cardioembolism. Stroke. 1992;23:486-491.

4. Eliasziw M, Streifler JY, Fox AJ, Hachinski VC, Ferguson GG, Barnett HJ. Significance of plaque ulceration in symptomatic patients with high-grade carotid stenosis. North American Symptomatic Carotid Endarterectomy Trial. Stroke. 1994;25:304-308.

5. Streifler JY, Eliasziw M, Fox AJ, Benavente OR, Hachinski VC, Ferguson GG, Barnett HJ. Angiographic detection of carotid plaque ulceration. Comparison with surgical observations in a multicenter study. North American Symptomatic Carotid Endarterectomy Trial. Stroke. 1994;25:1130-1132.

6. Wolf PA, Kannel WB, Sorlie P, McNamara P. Asymptomatic carotid bruit and risk of stroke: the Framingham study. JAMA. 1981;245:1442-1445.

7. Chambers BR, Norris JW. Outcome in patients with asymptomatic neck bruits. NEJM. 1986;315:860-865.

8. Heyman A, Wilkinson WE, Heyden S, Helms MJ, Bartel AG, Karp HR, Tyroler HA, Hames CG. Risk of stroke in asymptomatic persons with cervical arterial bruits: a population study in Evans County, Georgia. NEJM. 1980;302:838-841.

9. Wilterdink JL, Easton JD. Vascular event rates in patients with atherosclerotic cerebrovascular disease. Arch Neurol. 1992;49:857-863. 
10. Srinivasan J, Mayberg MR, Weiss DG, Eskridge J. Duplex accuracy compared with angiography in the Veterans Affairs Cooperative Studies Trial for symptomatic carotid stenosis. Neurosurgery. 1995;36:648-655.

11. Gillum RF. Epidemiology of carotid endarterectomy and cerebral angiography in the United States. Stroke. 1995;26:1724-1728.

12. Hankey GJ, Warlow CP, Sellar RJ. Cerebral angiographic risk in mild cerebrovascular disease. Stroke. 1990;21:209-222.

13. Antiplatelet Triallists' Collaboration. Secondary prevention of vascular disease by prolonged antiplatelet treatment. $B M J .1988 ; 296: 320-331$.

14. Special Writing Group, Fuster V, Dyken ML, Vokonas PS, Hennekens C. Aspirin as a therapeutic agent in cardiovascular disease. Circulation. 1993;87:659-675.

15. Hass WK, Easton JD, Adams Jr. HP, Pryse-Phillips W, Molony BA, Anderson S, Kamm B, Ticlopidine Aspirin Stroke Study Group. A randomized trial comparing ticlopidine hydrochloride with aspirin for the prevention of stroke in high-risk patients. NEJM. 1989;321:501-507.

16. Eastcott H, Pickering G, Rob C. Reconstruction of internal carotid artery in a patient with intermittent attacks of hemiplegia. Lancet. 1954;2:994-996.

17. Fields WS, Maslenikov V, Meyer JS, Hass WK, Remington RD, Macdonald M. Joint study of extracranial arterial occlusion. V. Progress report of prognosis following surgery or nonsurgical treatment for transient cerebral ischemic attacks and cervical carotid artery lesions. JAMA. 1970;211:1993-2003.

18. Shaw DA, Venables GS, Cartlidge NE, Bates D, Dickinson PH, Fields WS, Maslenikov V, Meyer JS, Hass WK, Remington RD, Macdonald M. Carotid endarterectomy in patients with transient cerebral ischaemia. Joint study of extracranial arterial occlusion. V. Progress report of prognosis following surgery or nonsurgical treatment for transient cerebral ischemic attacks and cervical carotid artery lesions. Journal of the Neurological Sciences. 1984;64:45-53. 
19. Pokras R, Dyken ML. Dramatic changes in the performance of endarterectomy for diseases of the extracranial arteries of the head. Stroke. 1988;19:1289-1290.

20. Winslow CM, Solomon DH, Chassin MR, Kosecoff J, Merrick NJ, Brook RH. The appropriateness of carotid endarterectomy. NEJM. 1988;318:721-727.

21. Easton JD, Sherman DG. Stroke and mortality rate in carotid endarterectomy: 228 consecutive operations. Stroke. 1977;8:565-568.

22. Barnett HJ, Plum F, Walton JN. Carotid endarterectomy - an expression of concern. Stroke. 1984;15:941-943.

23. North American Symptomatic Carotid Endarterectomy Trial (NASCET) investigators. Clinical alert: benefit of carotid endarterectomy for patients with highgrade stenosis of the internal carotid artery. Stroke. 1991;22:816-817.

24. North American Symptomatic Carotid Endarterectomy Trial Collaborators. Beneficial effect of carotid endarterectomy in symptomatic patients with high-grade carotid stenosis. NEJM. 1991;325:445-453.

25. North American Symptomatic Carotid Endarterectomy Trial (NASCET) Steering Committee. North American Symptomatic Carotid Endarterectomy Trial. Methods, patient characteristics, and progress. Stroke. 1991;22:711-720.

26. European Carotid Surgery Trialists' Collaborative Group. MRC European Carotid Surgery Trial: interim results for symptomatic patients with severe (70-99\%) or with mild (0-29\%) carotid stenosis. Lancet. 1991;337:1235-1243.

27. Mayberg MR, Wilson SE, Yatsu F, Weiss DG, Messina L, Hershey LA, Colling C, Eskridge J, Deykin D, Winn HR, Veterans Affairs Cooperative Studies Program 309 Trialist Group. Carotid endarterectomy and prevention of cerebral ischemia in symptomatic carotid stenosis. JAMA. 1991;266:3289-3294.

28. Loftus CM, Hopkins LN. Paradoxical indications for carotid artery reconstruction. Neurosurgery. 1995;36:99-100. 
29. Alexandrov AV, Bladin CF, Maggisano R, Norris JW. Measuring carotid stenosis. Time for a reappraisal. Stroke. 1993;24:1292-1296.

30. Hobson RW, Strandness DE Jr. Carotid artery stenosis: What's in the measurement? J Vasc Surg. 1993;18:1069-1070. Editorial.

31. Barnett HJ, Warlow CP. Carotid endarterectomy and the measurement of stenosis. Stroke. 1993;24:1281-1284.

32. The CASANOVA Study Group. Carotid surgery versus medical therapy in asymptomatic carotid stenosis. Stroke. 1991;22:1229-1235.

33. Mayo Asymptomatic Carotid Endarterectomy Study Group. Results of a randomized controlled trial of carotid endarterectomy for asymptomatic carotid stenosis. Mayo Clin Proc. 1992;67:513-518.

34. Lindblad B, Persson NH, Takolander R, Bergqvist D. Does low-dose acetylsalicylic acid prevent stroke after carotid surgery? A double-blind, placebocontrolled randomized trial. Stroke. 1993;24:1125-1128.

35. Kretschmer G, Pratschner T, Prager M, Wenzl E, Polterauer P, Schemper M, Ehringer H, Minar E. Antiplatelet treatment prolongs survival after carotid bifurcation endarterectomy. Analysis of the clinical series followed by a controlled trial. Ann Surg. 1990;211:317-322.

36. Hobson RW, Weiss DG, Fields WS, Goldstone J, Moore WS, Towne JB, Wright CB, The Veterans Affairs Cooperative Study Group. Efficacy of carotid endarterectomy for asymptomatic carotid stenosis. NEJM. 1993;328:221-227.

37. Barnett HJ, Haines SJ. Carotid endarterectomy for asymptomatic carotid stenosis. NEJM. 1993;328:276-279.

38. Executive Committee for the Asymptomatic Carotid Atherosclerosis Study. Endarterectomy for asymptomatic carotid artery stenosis. JAMA. 1995;273:14211428. 
39. European Carotid Surgery Trialists' Collaborative Group. Endarterectomy for moderate symptomatic carotid stenosis: interim results from the MRC European Carotid Surgery Trial. Lancet. 1996;347:1591-1593.

40. The European Carotid Surgery Trialists Collaborative Group. Risk of stroke in the distribution of an asymptomatic carotid artery. Lancet. 1995;345:209-212.

41. Warlow CP. Endarterectomy for asymptomatic carotid stenosis? Lancet. 1995;345:1254-1255.

42. Barnett HJ, Meldrum HE, Eliasziw M. The dilemma of surgical treatment for patients with asymptomatic carotid disease. Ann Intern Med. 1995;123:723-725.

43. Barnett HJ, Eliasziw M, Meldrum HE, Taylor DW. Do the facts and figures warrant a 10-fold increase in the performance of carotid endarterectomy on asymptomatic patients? Neurology. 1996;46:603-608.

44. Halliday AW, Thomas D, Mansfield A. The Asymptomatic Carotid Surgery Trial (ACST). Rationale and design. Steering Committee. Eur J Vasc Surg. 1994;8:703710.

45. Asaph JW, Janoff K, Wayson K, Kilberg L, Graham M. Carotid endarterectomy in a community hospital: a change in physicians' practice patterns. Am J Surg. 1991;161:616-618.

46. Norris JW, Zhu CZ. Silent stroke and carotid stenosis. Stroke. 1992;23:483-485.

47. Moore WS, Barnett HJ, Beebe HG, Bernstein EF, Brener BJ, Brott T, Caplan LR, Day A, Goldstone J, Hobson RW 2nd, Kempczinski RF, Matchar DB, Mayberg MR, Nicolaides AN, Norris JW, Ricotta JJ, Robertson JT, Rutherford RB, Thomas D, Toole JF, Trout HH 3rd, Wiebers DO. Guidelines for carotid endarterectomy. A multidisciplinary consensus statement from the ad hoc Committee, American Heart Association. Stroke. 1995;26:188-201.

48. Plecha EJ, King TA, Pitluk HC, Rubin JR. Risk assessment in patients undergoing carotid endarterectomy. Cardiovasc Surg. 1993;1:30-32. 
49. Goldstein LB, McCrory DC, Landsman PB, Samsa GP, Ancukiewicz M, Oddone EZ, Matchar DB. Multicenter review of preoperative risk factors for carotid endarterectomy in patients with ipsilateral symptoms. Stroke. 1994;25:1116-1121.

50. Sieber FE, Toung TJ, Diringer MN, Wang H, Long DM. Preoperative risks predict neurological outcome of carotid endarterectomy related stroke. Neurosurgery. 1992;30:847-854.

51. Fode NC, Sundt TM Jr, Robertson JT, Peerless SJ, Shields CB. Multicenter retrospective review of results and complications of carotid endarterectomy in 1981 . Stroke. $1986 ; 17: 370-376$.

52. McCrory DC, Goldstein LB, Samsa GP, Oddone EZ, Landsman PB, Moore WS, Matchar DB. Predicting complications of carotid endarterectomy. Stroke. 1993;24:1285-1291.

53. Steed DL, Peitzman AB, Grundy BL, Webster MW. Causes of stroke in carotid endarterectomy. Surgery. 1982;92:634-641.

54. Sundt TM, Sandok BA, Whisnant JP. Carotid endarterectomy. Complications and preoperative assessment of risk. Mayo Clin Proc. 1975;50:301-306.

55. Burke PA, Callow AD, O'Donnell TF Jr, Kelly JJ, Welch H. Prophylactic carotid endarterectomy for asymptomatic bruit. A look at cardiac risk. Arch Surg. $1982 ; 117: 1222-1227$.

56. Chimowitz MI, Weiss DG, Cohen SL, Starling MR, Hobson RW 2nd, Veterans Affairs Cooperative Study Group 167. Cardiac prognosis of patients with carotid stenosis and no history of coronary artery disease. Stroke. 1994;25:759-765.

57. Musser DJ, Nicholas GG, Reed JF 3rd. Death and adverse cardiac events after carotid endarterectomy. J Vasc Surg. 1994;19:615-622.

58. Urbinati S, Di Pasquale G, Andreoli A, Lusa AM, Ruffini M, Lanzino G, Pinelli G. Frequency and prognostic significance of silent coronary artery disease in 
patients with cerebral ischemia undergoing carotid endarterectomy. Am J Cardiol. 1992;69:1166-1170.

59. Yeager RA, Moneta GL, McConnell DB, Neuwelt EA, Taylor LM Jr, Porter JM. Analysis of risk factors for myocardial infarction following carotid endarterectomy. Arch Surg. 1989;124:1142-1145.

60. Rihal CS, Gersh BJ, Whisnant JP, Rooke TW, Sundt TM Jr, O'Fallon WM, Ballard DJ. Influence of coronary heart disease on morbidity and mortality after carotid endarterectomy: a population-based study in Olmsted County, Minnesota (1970-1988). J Am Coll Cardiol. 1992;19:1254-1260.

61. Mackey WC, O'Donnell TF Jr, Callow AD. Cardiac risk in patients undergoing carotid endarterectomy: impact on perioperative and long-term mortality. $J$ Vasc Surg. 1990;11:226-233.

62. Urbinati S, Di Pasquale G, Andreoli A, Lusa AM, Carini G, Grazi P, Labanti G, Passarelli P, Corbelli C, Pinelli G. Preoperative noninvasive coronary risk stratification in candidates for carotid endarterectomy. Stroke. 1994;25:2022-2027.

63. Brook RH, Park RE, Chassin MR, Solomon DH, Keesey J, Kosecoff J. Predicting the appropriate use of carotid endarterectomy, upper gastrointestinal endoscopy, and coronary angiography [see comments]. NEJM. 1990;323:11731177.

64. Chassin MR, Kosecoff J, Park RE, Winslow CM, Kahn KI, Merrick NJ, Keesey J, Fink A, Solomon DH, Brook RH. Does inappropriate use explain geographic variations in the use of health care services? A study of three procedures. JAMA. 1987;258:2533-2537.

65. Merrick NJ, Brook RH, Fink A, Solomon DH. Use of carotid endarterectomy in five California Veterans Administration medical centers. JAMA. 1986;256:25312535. 
66. Coyne TJ, Wallace MC. Surgical referral for carotid artery stenosis - the influence of NASCET. Can J Neurol Sci. 1994;21:129-132.

67. Rothwell PM, Slattery J, Warlow CP. A systematic review of the risks of stroke and death due to endarterectomy for symptomatic carotid stenosis. Stroke. 1996;27:260-265. 


\section{Chapter 2}

\section{a Regional performance of CAROTID ENDARTERECTOMY:}

\section{Appropriateness, OUtcomes, aNd Risk Factors for Complications}

A version of this chapter has been submitted for publication. Wong JH, Findlay JM, Suarez-Almazor ME, A Regional Performance of Carotid Endarterectomy: Appropriateness, Outcomes, and Risk Factors for Complications. 


\section{Summary}

Objective Guided by randomized controlled trials evaluating carotid endarterectomy (CEA), we examined the appropriateness of CEAs performed in our city, and determined the incidences and risk factors for postoperative stroke, death, and cardiac complications.

Methods We retrospectively reviewed 291 consecutive, CEAs performed in our region over 18 months using health records. Based upon randomized controlled trial results and standardized remeasurements of angiographic carotid stenoses, indications for CEA were considered appropriate for symptomatic carotid stenoses $\geq 70 \%$, uncertain for $<70 \%$ symptomatic or $\geq 60 \%$ asymptomatic stenoses, or inappropriate for $<60 \%$ asymptomatic stenoses and for patients with preoperative neurological or medical instability.

Results Forty-one percent of patients (118/291) were asymptomatic. Surgical indications were appropriate in $33 \%$ of cases (92/281), uncertain in $49 \%$ (138/281), and inappropriate in $18 \%(51 / 281)$. Stroke or death occurred within 30 days postoperatively in $5.2 \%(9 / 174)$ of symptomatic patients and $5.1 \%(6 / 117)$ of asymptomatic patients. At least one cardiac complication (angina, congestive heart failure [CHF], dysrhythmia, or myocardial infarction) developed in $8.9 \%$ (26/291). Independent preoperative risk factors for stroke or death were histories of angina or CHF, and lack of antiplatelet medication, and for cardiac complications were age $>75$ years and a history of CHF.

Conclusions Almost one in five patients underwent CEA inappropriately, which was most commonly due to apparent overestimation of stenosis severity, and one-half had uncertain indications. Our high complication rate possibly negated any overall surgical benefit in the large group of asymptomatic patients. 
Only a decade ago, the practice of carotid endarterectomy (CEA) was seriously questioned. ${ }^{1,2}$ This was mainly due to its then unproven efficacy in stroke prevention, but contributing to these concerns were descriptions of its use for what appeared to be inappropriate indications, ${ }^{3}$ as well as reports of unacceptably high complication rates in several surgical audits. ${ }^{4-8}$ In response to this uncertainty, multicenter, randomized, controlled trials were launched which subsequently validated the use of CEA under certain circumstances. ${ }^{9-13}$ In these studies, carotid stenoses were measured in a standardized fashion and treatment complications were carefully monitored and reported. Since the results of these trials have disseminated throughout the medical community and contributed to a large resurgence in the use of CEA, ${ }^{14}$ we wished to reexamine the issues of appropriateness and complications of CEA as it is currently practiced in our region.

Using the results of the recently reported randomized trials examining CEA as guidelines, the goal of this study was to determine the appropriateness and complication rates of CEAs performed in our city over a recent 18 month period. Part of this analysis required an assessment of the accuracy of preoperative ultrasonography and angiography practiced in our region. We also wished to determine any risk factors in our patient population significantly predictive of postoperative stroke or death, and cardiac complications.

\section{Patients and Methods}

We performed a retrospective cohort study of all patients who underwent CEA in Edmonton, Alberta, Canada from April 1, 1994 to September 30, 1995. The cohort consisted of 291 cases of CEA performed on 265 patients by nine surgeons from the neurosurgical, general surgery, and vascular surgery services, from four teaching 
hospitals (two of which were tertiary-care centers). Given that Canada's universal healthcare system guarantees accessibility, and the fact that our city's hospitals serve as referral centers for about 1.6 million people from an expansive geographic area, this study may be considered a population-based analysis. Clinical and radiological information was collected primarily by examination of in-hospital medical records, and, if necessary, supplemented through review of available office records of individual surgeons. Patient follow-up was conducted through telephone interview of patients or their families, and/or survey of ambulatory care records from the operating surgeons' offices. Additionally, information about death after hospital discharge for all patients was obtained through database searches of the provincial government mortality registry using linkage analyses with name and birth date.

Carotid angiograms were remeasured in a standardized fashion by one investigator (J.H.W.) who was blinded to patient identity and the original reported degree of stenosis. Angiograms that were difficult to interpret were evaluated in consultation with the senior author (J.M.F.) in a similar blinded manner. The angiographic method of measurement used was that of the North American Symptomatic Carotid Endarterectomy Trial (NASCET), i.e. by comparing the greatest degree of linear diameter stenosis of the internal carotid artery (ICA) at the carotid bifurcation to the diameter of the distal, normal ICA. ${ }^{15}$ These results were compared to the angiographic percentage stenosis appearing on the original radiologist's report and the reported range of stenosis determined by ultrasonography. The presence or mention of an angiographic flow-limiting, critical stenosis resulting in the appearance of a distally thin ICA, or a delay in contrast filling of the ICA compared to the adjacent external carotid artery, was classified as a $95 \%$ stenosis. ${ }^{16}$ Carotid bifurcation plaques were graded according to their angiographic appearance as being ulcerated, irregular, or smooth. ${ }^{17}$ The distal ipsilateral cerebral vasculature was assessed for arterial stenosis, defined as narrowing greater than $50 \%$ of the local luminal diameter. Ultrasonography data was collected from the actual ultrasound 
report as obtained from the in-hospital record or referring diagnostic facility. Angiography or ultrasonography reports using only subjective descriptors such as "severe" to quantify carotid stenosis were excluded from comparison analyses.

The appropriateness of operative indications was determined based upon a review of five recent randomized controlled trials examining $\mathrm{CEA}^{9-13}$ and clinical practice guidelines established by both the American Heart Association ${ }^{18}$ and the Canadian Neurosurgical Society (Cerebrovascular writing group for the Canadian Neurosurgical Society, unpublished document). Using these criteria in conjunction with our NASCET remeasurement values, the appropriateness of CEA for each patient examined in this study was classified into one of the following categories: 1) appropriate for symptomatic patients with isolated and surgically accessible carotid stenoses greater than or equal to $70 \% ; 2$ ) uncertain for patients with either symptomatic stenoses of less than $70 \%$ or asymptomatic stenoses greater than or equal to $60 \%$, or; 3 ) inappropriate for patients with asymptomatic stenoses of less than $60 \%$, and for those patients with significant neurological instability or high risk medical conditions. Preoperative neurological instability, based on criteria as originally described by Sundt et $\mathrm{al}^{19}$ and more recently validated in a retrospective study, ${ }^{20}$ was defined as a progressing neurological deficit or a neurological deficit within one day prior to CEA. High-risk preoperative medical conditions were defined as unstable angina (defined as angina developing at rest or of new onset), myocardial infarction within 3 months prior to CEA, or uncontrolled congestive heart failure (CHF). Patients were considered symptomatic from their carotid disease if there was a documented history of any prior cerebral or retinal ischemia referable to the vascular territory of the stenotic carotid artery, i.e. ipsilateral transient ischemic attack, stroke, amaurosis fugax, or retinal infarction. Patients with non-hemispheric or non-retinal symptoms, such as dizziness, syncope, or bilateral visual difficulties, were regarded as being asymptomatic from their carotid disease. 
The primary outcome event in this analysis was stroke or death occurring within 30 days of surgery. Any hemispheric neurological deficit lasting greater than 24 hours was classified as a stroke. A major stroke was defined as one producing a significant functional deficit. For example, a patient rendered incapable of independent activities of daily living or requiring further rehabilitation was classified as having a major deficit, whereas mild weakness in a patient otherwise capable of independent ambulation and returning home upon discharge was classified as a minor stroke. The degree of clinical recovery after hospital discharge was not assessed. A secondary outcome event was the development of at least one postoperative in-hospital cardiac complication (namely, angina, CHF, dysrhythmia, or myocardial infarction).

Data was collected using a computer database (FileMaker Pro 2.1, Claris Corporation, Santa Barbara, CA, USA) and analyzed with statistical software (SPSS 6.1, SPSS Incorporated, Chicago, IL, USA). Means were expressed \pm standard error of the mean. The pooled chance-corrected measure of agreement between the original interpretation and the NASCET remeasurement value of the angiograms was expressed as a kappa (K) summary statistic. Univariate testing utilized Chi-square and Fisher's exact tests for comparison of proportions. Measures of association between risk factors and outcome events were expressed as odds ratios (ORs) with $95 \%$ confidence intervals (CI). Level of significance was set at $P \leq 0.05$ and all tests were two-tailed. The associations between risk factors and outcome events were also evaluated with multivariate analyses using logistic regression models. Dependent variables were the dichotomous outcomes of stroke or death, and cardiac complications. Independent variables used in these models included those listed in table 2-5 as well as the following dichotomous variables: history of diabetes mellitus, history of claudication, history of valvular heart disease, preoperative neurological instability (present or absent), ${ }^{19,20}$ preoperative systolic blood pressure ( $>160 \mathrm{~mm} \mathrm{Hg}$ or $\leq 160 \mathrm{~mm} \mathrm{Hg}$ ), carotid plaque irregularity (present or absent), ${ }^{17}$ carotid plaque ulceration (present or absent), ${ }^{17}$ intraoperative shunting (yes or no), surgical 
service (neurosurgical or non-neurosurgical), and postoperative bradycardia ( $<60$ or $\geq 60$ beats per minute). A stepwise procedure was used to include variables in the model using a probability of 0.05 for variable inclusion and 0.10 for exclusion.

\section{Results}

The mean patient age was $67.8 \pm 0.5$ years and $58 \%$ of patients were male (170/291). Patient characteristics are summarized in table 2-1. Forty-one percent of operations (118/291) were for asymptomatic stenosis, and the remainder were for symptomatic disease. One hundred and twenty-two patients were operated on by one of two neurosurgeons, and 169 patients were operated on by one of seven general or vascular surgeons.

All patients had undergone carotid or cerebral angiography prior to surgery, and 97\% (281/291) of cases had angiograms available for remeasurement. For this analysis, comparisons were made with respect to each artery (both operated and non-operated) rather than per patient. Thirty arteries were excluded since the original radiologist did not numerically quantify the degree of stenosis narrowing. When the angiographic stenoses on both operated and non-operated sides were remeasured with the NASCET method, there was an overall moderate agreement with the original radiologist's interpretation $(\mathrm{K}=0.72[0.64$ to $0.80,95 \% \mathrm{CI}$ ] for symptomatic stenosis, and $\mathrm{K}=0.67$ [0.57 to 0.77 , 95\% CI for asymptomatic stenosis) (see tables 2-2a and 2-2b). The method of angiographic measurement used by the original radiologist could not be reliably determined in this study.

Stenoses on ultrasonography in our region are reported in percentage ranges rather than specific values. No attempt was made in this study to establish standards of ultrasonographic equipment or technique. Of the 248 patients who underwent carotid ultrasonography as the initial diagnostic test, 219 had ultrasonography reports (88\%) 
available for review, and 214 had both ultrasonographic and angiographic studies examined (86\%). Ultrasonographic accuracy was investigated per artery, (both operated and non-operated), rather than per patient. After excluding reports that did not quantify carotid disease, 392 arteries were left for analysis. As shown in tables 2-3a and 2-3b, preoperative ultrasonography generally had a high sensitivity ( $89 \%$ and $97 \%$ ) but only moderate specificity, $58 \%$ and $67 \%$, for carotid disease of greater than or equal to $50 \%$ and $80 \%$, respectively.

Using our criteria of appropriateness in conjunction with the NASCET remeasurement values, the appropriateness of CEA was determined for our patient population and the results are summarized in table 2-4. Appropriate indications for CEA were found in $33 \%$ of patients $(92 / 281)$, while $49 \%$ had indications considered uncertain (138/281), and inappropriate surgical indications were found in $18 \%$ of patients $(51 / 281)$. Of the 51 cases with inappropriate indications, 23 (45\%) were asymptomatic patients who were originally incorrectly measured as having $\geq 60 \%$ stenosis, 14 (27\%) were asymptomatic patients who underwent surgery despite stenoses correctly measured at less than $60 \%$, eight (16\%) were patients with preoperative neurological instability, and six (12\%) were patients at high preoperative medical risk. Recognizing the marked benefit of CEA for severe symptomatic disease that was found in NASCET, ${ }^{9}$ and therefore the possible tendency to operate on patients with stenoses that approached this degree of narrowing, we re-analyzed the data using modified criteria where symptomatic stenoses $\geq 65 \%$ were considered appropriate. However, this only minimally increased the proportion of appropriate indications to $37 \%(104 / 281)$ and decreased uncertain indications to $45 \%(126 / 281)$.

Inappropriate use of CEA was found to vary widely among individual surgeons, ranging from $0 \%$ to $33 \%,(P=0.07$, degrees of freedom $[D F]=8$, Chi square test). Fourteen percent of CEAs performed by the neurosurgical service were classified as inappropriate, versus $21 \%$ inappropriate CEAs for the non-neurosurgical services, a 
difference which was not statistically significant $(\mathrm{P}=0.15$, Chi square test). Uncertain indications for CEA were found in $33 \%$ to $67 \%$ of individual surgeon's series, $P=0.26$, $\mathrm{DF}=8$, Chi square test). When stratified according to surgical service, neurosurgeons utilized CEA for uncertain indications significantly less often than their surgical colleagues, (40\% versus $55 \%, P=0.006$, Chi square test).

Overall, in this series there were six major strokes and five minor postoperative strokes occurring within 30 days of surgery. (Two additional minor strokes which developed as a result of angiography in previously asymptomatic patients were not included in the outcome analysis.) All strokes that occurred in this study were ischemic, and all were in the territory of the operated carotid artery. Of the four deaths that occurred in this series, two were due to myocardial infarction, one was due to ischemic bowel secondary to cardiovascular causes, and one was due to interstitial pneumonitis. The combined stroke or death rate in this series was $5.2 \pm 1.7 \%$ for symptomatic patients (9/174) and 5.1 $\pm 2.0 \%$ for asymptomatic patients (6/117). Although a broad range of stroke or death rates for individual surgeons was observed ( 0 to $33 \%$ ), the relatively smail number of cases performed by the large number of surgeons in this analysis may have contributed to an inability to statistically associate stroke or death rates to individual surgeon $(P=0.22$, Chi square test, $D F=8)$, or to surgical specialty. The combined stroke or death rate was $4.1 \%$ for neurosurgery and $5.9 \%$ for all other surgical specialties combined ( $P=0.49$, Chi square test).

Significant risk factors for stroke or death were determined by univariate analysis and multiple logistic regression and are summarized in tables 2-5 and 2-6. Independent preoperative risk factors for stroke or death by multivariate analysis were a history of angina, a history of CHF, and lack of preoperative antiplatelet medication. At least one cardiac complication developed in $8.9 \%$ of patients $(26 / 291)$. The risk factors for cardiac complications, determined by univariate and multivariate analyses, are also summarized in tables 2-5 and 2-6. Multiple logistic regression yielded age greater than 75 years and a 
history of CHF as being significant independent variables associated with cardiac complications.

\section{Discussion}

\section{Appropriateness of Carotid Endarterectomy}

Assessments of the appropriateness of CEA in surgical series or populations of operated patients are rare. Winslow and colleagues examined the surgical indications of 1302 Medicare patients from three geographic areas who underwent CEA in $1981 .{ }^{3}$ Using appropriateness guidelines established by a multidisciplinary panel of experts, they determined that $35 \%$ of these patients had surgery for appropriate reasons, $32 \%$ had equivocal surgical indications, and 32\% underwent CEA inappropriately. Of this latter group of patients, $48 \%$ underwent surgery for minimal carotid stenosis, $11 \%$ were at excessively high preoperative risk, $9 \%$ had cerebrovascular symptoms contralateral to the operated side, and $6 \%$ received surgery for carotid occlusion. The authors concluded that CEA was substantially overused in the regions studied, and since the perioperative stroke or death rate was $9.8 \%$ in their study group, they felt that any benefit at all from CEA was questionable. Application of these same criteria to 107 cases of CEA in five Veterans Administration hospitals in 1981 revealed that $55 \%$ of surgeries were appropriate, and $32 \%$ were equivocal. ${ }^{21}$ Thirteen percent of cases were clearly inappropriate in that study, mostly due to operation on patients with carotid occlusion and asymptomatic patients with moderate stenoses at higher surgical risk.

On a smaller scale, Asaph and colleagues found that in a retrospective community surgical audit of 243 patients from 1986-1987, 37\% of CEA patients were operated on for $<80 \%$ asymptomatic stenosis. ${ }^{22}$ After these results were publicized, a local surgical committee formulated the following appropriate indications for CEA: carotid lesions causing transient ischemic attack or reversible ischemic neurological deficit; "significant" 
carotid stenoses causing stroke with subsequent recovery; asymptomatic carotid stenoses greater than $80 \%$; or any other reason if supported by a disinterested third party. As a result, over the succeeding 21 months, there was a drop in the number of operations performed, the surgical complication rate, and the number of "inappropriate" operations for asymptomatic carotid disease.

Such concerns over the appropriateness of CEA, along with its unproven efficacy and possible excessive use ${ }^{1-3}$ resulted in the initiation of a number of randomized, controlled, CEA trials, including NASCET, ${ }^{9}$ the European Carotid Surgery Trial (ECST), ${ }^{10}$ the symptomatic and asymptomatic American Veterans Affairs trials, ${ }^{11,12}$ and the Asymptomatic Carotid Atherosclerosis Study (ACAS). ${ }^{13}$ The published results of these studies have supplied evidence to support different indications for CEA with correspondingly variable degrees of certainty, and have also provided benchmarks for acceptable complication rates associated with each indication (table 2-7). Although NASCET and ECST measured carotid stenosis in a different way, the preliminary results of both indicate that CEA is much more effective than medical therapy in preventing stroke for severe, symptomatic stenoses, providing that the perioperative stroke or death rate is less than $6 \% .{ }^{18}$ Surgery for patients with symptomatic stenoses $<70 \%$ was designated an uncertain indication for CEA in our analysis, since NASCET had not yet completed comparing CEA to medical therapy for such patients during our study period and time of manuscript preparation. Since NASCET specifically excluded patients with progressing or disabling neurological deficits, and those with uncontrolled medical illness, and since previous studies have suggested that patients with these risk factors have a high risk of postoperative stroke, 19,20 patients found with these features in our review were considered inappropriate candidates for surgery.

Asymptomatic stenoses greater than $60 \%$ (as determined by the NASCET method) were classified as an uncertain indication for CEA in our analysis. The only randomized controlled study to date indicating efficacy of CEA for stroke prevention in asymptomatic 
patients is ACAS, and the results of that study require careful interpretation. ${ }^{13}$ Although this trial demonstrated that the risk of stroke or death was significantly lowered in the surgical group, the absolute risk reduction with CEA was only slightly more than $1 \%$ per year projected over 5 years. As well, major strokes were not prevented, women did not appear to benefit from CEA, and the overall positive result for surgery was only realized with a very low $2.3 \%$ perioperative stroke or death rate. These concerns, coupled with the fact that the natural history of asymptomatic carotid stenosis is fairly benign with an annual stroke or death risk on the order of only $1-2 \%, 23,24$ suggest that the results of ACAS may be statistically but not clinically significant. It may be argued that before the ACAS results were first published in December $1994,{ }^{25}$ halfway during our study period, there was even less compelling scientific evidence to suggest asymptomatic stenosis was a good indication for CEA. Because the benefit of CEA for asymptomatic stenosis seems marginal and dependent upon both the patients treated and a very low operative complication rate, we decided $a$ priori in our analysis that this indication would be considered "uncertain", rather than unequivocally "appropriate".

Data from randomized controlled trials have afforded an opportunity to base determinations of CEA appropriateness upon objective evidence of surgical efficacy. Previous studies evaluating the appropriateness of CEA may have been limited by biases in the opinions of what was considered appropriate surgery. ${ }^{26-29}$ Our analysis is also unique in that it links surgical appropriateness with standardized carotid stenosis remeasurements. Our choice of the NASCET method of measurement was based upon its relatively high intra- and inter-observer reliability, ${ }^{30}$ and its use in most of the randomized, controlled CEA trials that have provided the basis of our classification of appropriateness.9, 11-13, 31 The results of our study, where reasonable but not strong agreement was found between the original radiologist's interpretation and the remeasurement value, validates previous concerns that CEA may be performed on the basis of inaccurate or nonuniform stenosis measurements. ${ }^{32}$ However, the actual impact 
of this discrepancy on our patients' management could not be determined since it is not known if each surgeon in our study based treatment upon the radiologist's report or upon personal review and measurement of the angiogram. The fact that the most common discrepancy found was an overestimation of the stenosis severity suggests that surgeons were either not consistently and accurately remeasuring angiograms with the NASCET method prior to making a decision regarding surgery, or making management decisions only partly based on stenosis severity.

We found that the sensitivity of ultrasound for assessing angiographic stenoses in our study population was fairly high although the specificity of this imaging technique was only moderate. As well, the reliability of ultrasonography in our region may be suspect as the positive predictive value of ultrasonography was only $50 \%$ for detecting severe stenoses $\geq 80 \%$. In our series, carotid ultrasound tended to overestimate the actual severity of carotid stenosis. Other studies have shown ultrasonography to be less accurate in assessing mild and moderate stenoses than severe stenoses, with one study demonstrating test sensitivities ranging from $25-92 \%$, depending on the degree of vessel narrowing. $33-35$

In our study, combining the best indication for surgery as ascertained from patient records with the carotid stenosis remeasurement value, we found that $49 \%$ of patients who underwent CEA had an uncertain indication, and that the majority of these patients had asymptomatic stenoses $\geq 60 \%$. Inappropriate CEAs were found in $18 \%$ of our patient population, or in almost one in every five patients overall. This group was made up largely of patients with $<60 \%$ asymptomatic stenoses, of which $62 \%(23 / 37)$ had original angiographic readings that overestimated the NASCET remeasurement value. The remainder in this group underwent surgery in the face of neurological instability, or highrisk medical comorbidity. An argument can be made, however, to consider neurologically unstable patients separately, rather than as inappropriate surgical candidates a priori. Although unproven, it may be that some of these patients may in fact benefit overall from 
CEA, even with an elevated attendant perioperative complication rate, if their risk of stroke or death without surgery is greater than with CEA.

Since efficacy of CEA for symptomatic stenoses $<70 \%$ may yet be shown in the continuing part of NASCET, perhaps the most concerning finding in our analysis was the large proportion of patients undergoing surgery for asymptomatic stenosis. Available evidence suggests any modest benefit from surgery for asymptomatic patients is realized only with a very low perioperative complication rate which may be difficult to achieve outside the research setting.

\section{Complications of Carotid Endarterectomy}

A recent literature review of studies published since 1980 which examined the results of CEA performed for symptomatic carotid stenosis found a mean stroke or death rate of $5.6 \%$ (4.4 to $6.9 \%, 95 \% \mathrm{CI}){ }^{36}$ For the symptomatic subgroup of patients in our series, the $5.2 \%$ stroke or death rate was similar to this and the $5.8 \%$ rate found in NASCET. ${ }^{9}$ However, the $5.1 \%$ postoperative stroke or death rate in our asymptomatic patients was higher than the $3.4 \%$ rate found in a review of asymptomatic series, ${ }^{37}$ and significantly more than the corresponding $1.2 \%$ rate found in ACAS (Fisher's exact test, $\mathrm{P}=0.01) .^{13}$ This comparatively greater complication rate for asymptomatic patients in our series is unexplained, but probably negated any overall benefit from CEA for this subgroup of patients in our region. Higher complication rates in community-based studies, as compared to randomized controlled trials, are not unexpected. In randomized controlled trials, artificial constraints such as stringent inclusion and exclusion criteria, generally excellent patient care, and close patient follow-up, may result in better outcomes than in routine clinical practice.

Several groups have described potential risk factors for surgical complications after CEA.8, 38-41 In 1975, Sundt et al provided evidence that patients with certain cardiovascular and neurological risk factors were at highest risk for postoperative myocardial infarction and stroke. ${ }^{19}$ Some of these same risk factors have been confirmed 
statistically in a retrospective analysis of 1160 CEA patients. ${ }^{20}$ The authors of this latter study found seven predictors that can stratify candidates for CEA at higher risks of stroke and cardiac complications: age over 75 years, symptomatic (versus asymptomatic) stenosis, severe hypertension, CEA in preparation for coronary artery surgery, a history of angina, intraluminal thrombus apparent on angiography, and intracranial arterial stenosis. Our analysis of a smaller group of patients identified a history of angina, a history of CHF, and lack of antiplatelet agent use prior to surgery as preoperative independent variables associated with stroke or death.

Although risk factors for cardiac complications alone following CEA have been less commonly studied in the literature, patients undergoing CEA frequently harbor occult or symptomatic cardiac disease. ${ }^{42-49}$ Our present study identified age over 75 years and a history of CHF as independent preoperative variables predictive of cardiac complications after CEA. The detection of these risk factors may allow the preoperative identification of high-risk patients who may then be given more intensive perioperative monitoring or treatment. ${ }^{50}$

The findings of this study emphasize the usefulness of a regional analysis in uncovering local clinical concerns. It deserves mention, however, that surgical audits such as reported here are time-consuming and expensive endeavors, and require the interpretive skills of individuals familiar with cerebrovascular disease. We determined that CEA may be overused in our region due to the substantial number of operations for inappropriate and uncertain indications. In particular, the observed high complication rate suggests restricting the use of CEA for asymptomatic patients in our region. Since estimates have placed the proportion of operations for asymptomatic carotid disease at $25-50 \%$ of all CEAs performed in the United States, ${ }^{51}$ the disturbing findings of our study may be reflective of similar problems in other communities. As additional information from randomized, controlled trials becomes available, 52 thus more fully defining the indications 
for CEA, appropriateness classifications can be revised, new audits undertaken, and previous audits can be reanalyzed.

In summary, the combined rate of uncertain and inappropriate surgeries was high at $67 \%$ in our healthcare region, with half of all patients undergoing CEA for uncertain indications. Inappropriate surgery was seen in about one in five patients in this analysis and was related mainly to overestimation of mild and moderate asymptomatic carotid stenoses, but was also due to the use of CEA in the presence of significant neurological and medical instability in some instances. The uniform use of a standard method of angiographic measurement of carotid stenosis may reduce the rate of surgeries for uncertain and inappropriate indications. A substantial proportion of our study population was asymptomatic, and any benefit of surgery for these patients was overshadowed by a significant risk of postoperative stroke or death. The preoperative identification of highrisk patients through risk factor analysis may offer an opportunity to reduce complication rates. Independent local audits of surgical performance are recommended to identify areas of concern at a regional level. 


\section{Tables}

TABLE 2-1. Selected characteristics of patient population

\begin{tabular}{lc}
\hline \multicolumn{1}{c}{ Characteristic } & Number of cases (\%) \\
\hline Age >75 years & $61(21 \%)$ \\
History of angina pectoris & $61(21 \%)$ \\
Prior CABG/angioplasty & $46(16 \%)$ \\
CAD & $104(36 \%)$ \\
History of CHF & $16(6 \%)$ \\
COPD & $64(22 \%)$ \\
Diabetes mellitus & $68(23 \%)$ \\
Cardiac dysthythmia & $13(5 \%)$ \\
Current cigarette use & $99(34 \%)$ \\
History of hypertension & $180(62 \%)$ \\
Hyperlipidemia & $124(43 \%)$ \\
History of MI & $58(20 \%)$ \\
Claudication & $40(14 \%)$ \\
Valvular heart disease & $18(6 \%)$ \\
Renal insufficiency & $30(10 \%)$ \\
\hline Prior vascular surgery & $92(32 \%)$ \\
\hline
\end{tabular}

CABG indicates coronary artery bypass grafting; CAD, coronary artery disease; CHF, congestive heart failure; COPD, chronic obstructive pulmonary disease; MI, myocardial infarction. 
TABLE 2-2A. Accuracy of preoperative angiography for symptomatic carotid stenoses

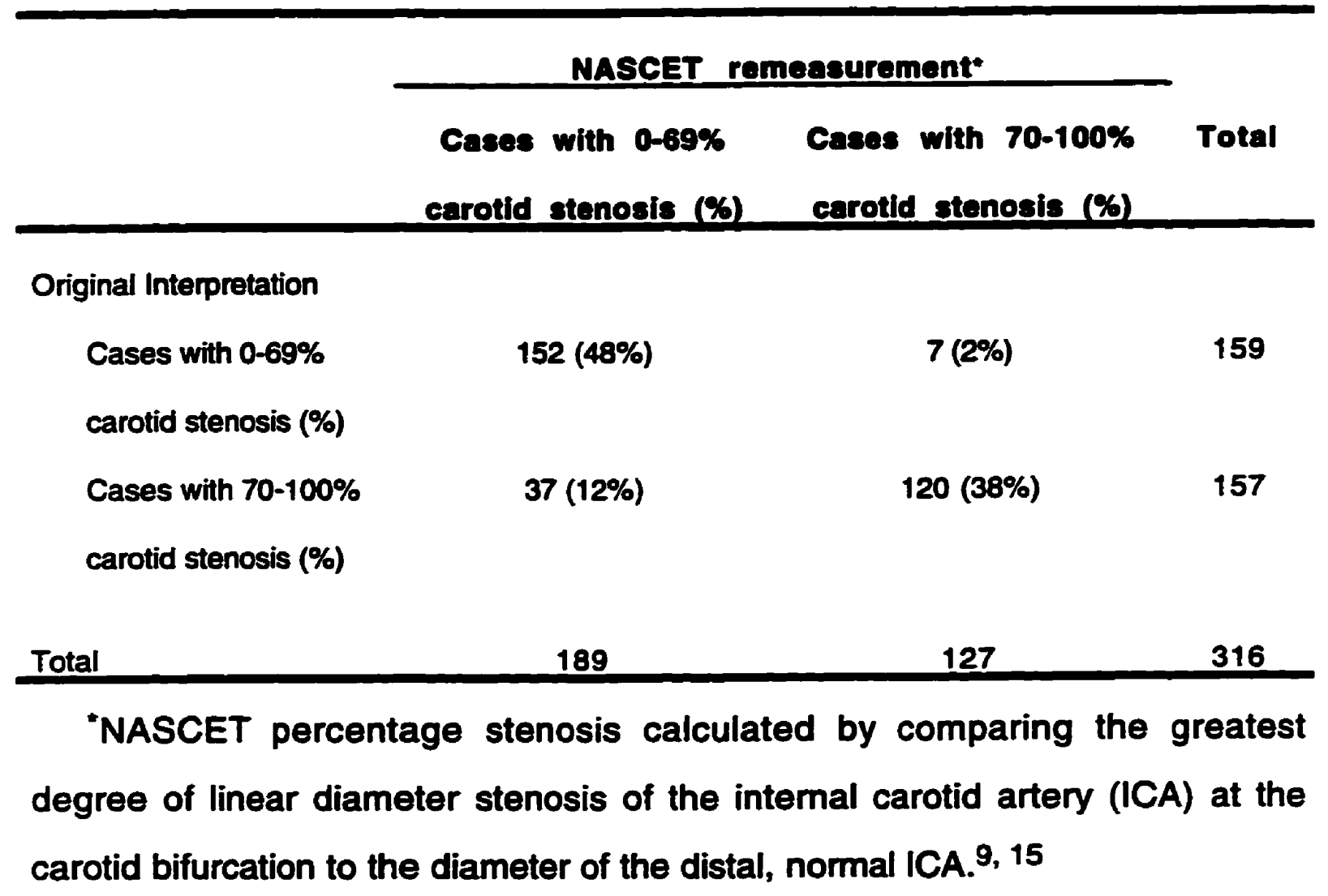


TABLE 2-2B. Accuracy of preoperative angiography for asymptomatic carotid stenoses

\begin{tabular}{|c|c|c|c|}
\hline & \multicolumn{2}{|c|}{ NASCET remeasurement* } & \multirow[b]{2}{*}{ Total } \\
\hline & $\begin{array}{l}\text { Cases with } 0-59 \% \\
\text { carotid stenosis }(\%)\end{array}$ & $\begin{array}{l}\text { Cases with } 60-100 \% \\
\text { carotid stenosis }(\%)\end{array}$ & \\
\hline \multicolumn{4}{|l|}{ Original Interpretation } \\
\hline $\begin{array}{l}\text { Cases with } 0-59 \% \\
\text { carotid stenosis (\%) }\end{array}$ & $72(34 \%)$ & $3(1 \%)$ & 75 \\
\hline $\begin{array}{l}\text { Cases with } 60-100 \% \\
\text { carotid stenosis (\%) }\end{array}$ & $32(15 \%)$ & $107(50 \%)$ & 139 \\
\hline Total & 104 & 110 & 214 \\
\hline
\end{tabular}

"NASCET percentage stenosis calculated by comparing the greatest degree of linear diameter stenosis of the internal carotid artery (ICA) at the carotid bifurcation to the diameter of the distal, normal ICA. ${ }^{9}, 15$ 
TABLE 2-3A. Accuracy of ultrasonography compared to NASCET angiography for carotid stenoses $\geq 50 \%$

\section{Angiography*}

Cases with 50-100\% Cases with 0-49\% Total

carotid stenosis (\%) carotid stenosis (\%)

Ultrasonography

Cases with $50-100 \%$

$241(61 \%)$

$61(16 \%)$

302

carotid stenosis (\%)

Cases with 0-49\%

$7(2 \%)$

$83(21 \%)$

90

carotid stenosis (\%)

"NASCET percentage stenosis calculated by comparing the greatest degree of linear diameter stenosis of the internal carotid artery (ICA) at the carotid bifurcation to the diameter of the distal, normal ICA.9, 15

Sensitivity $=97 \%$, specificity $=58 \%$, positive predictive value $=80 \%$, negative predictive value $=92 \%$. 
TABLE 2-3B. Accuracy of ultrasonography compared to NASCET angiography for carotid stenoses $\geq 80 \%$

\begin{tabular}{|c|c|c|c|}
\hline & \multicolumn{2}{|c|}{ Angiography" } & \multirow[b]{2}{*}{ Total } \\
\hline & $\begin{array}{l}\text { Cases with } 80-100 \% \\
\text { carotid stenosis }(\%)\end{array}$ & $\begin{array}{l}\text { Cases with } 0-79 \% \\
\text { carotid stenosis }(\%)\end{array}$ & \\
\hline \multicolumn{4}{|l|}{ Ultrasonography } \\
\hline $\begin{array}{l}\text { Cases with } 80-100 \% \\
\text { carotid stenosis (\%) }\end{array}$ & $93(24 \%)$ & $94(24 \%)$ & 187 \\
\hline $\begin{array}{l}\text { Cases with } 0-79 \% \\
\text { carotid stenosis (\%) }\end{array}$ & $11(3 \%)$ & $194(49 \%)$ & 205 \\
\hline Total & 104 & 288 & 392 \\
\hline
\end{tabular}

"NASCET percentage stenosis calculated by comparing the greatest degree of linear diameter stenosis of the internal carotid artery (ICA) at the carotid bifurcation to the diameter of the distal, normal ICA.9, 15

Sensitivity $=89 \%$, specificity $=67 \%$, positive predictive value $=50 \%$, negative predictive value $=95 \%$. 
TABLE 2-4. Appropriateness of carotid endarterectomy

\begin{tabular}{|c|c|c|}
\hline Level of appropriateness & Subcategories & $\begin{array}{l}\text { Number of cases" } \\
\text { (\% total, } 95 \% \text { Cl) }\end{array}$ \\
\hline Appropriate & Symptomatic stenoses $\geq 70 \%$ & $92(33 \%, 27$ to $38 \%)$ \\
\hline \multirow[t]{2}{*}{ Uncertain } & Symptomatic stenoses $<70 \%$ & $63(22 \%, 18$ to $27 \%)$ \\
\hline & Asymptomatic stenoses $\geq 60 \%$ & $75(27 \%, 22$ to $32 \%)$ \\
\hline \multirow[t]{3}{*}{ Inappropriate } & Asymptomatic stenoses $<60 \%$ & $37(13 \%, 9$ to $17 \%)$ \\
\hline & Neurologically unstablet & $8(3 \%, 1$ to $6 \%)$ \\
\hline & Medically unstable $\ddagger$ & $6(2 \%, 1$ to $5 \%)$ \\
\hline
\end{tabular}

"Two hundred and eighty-one angiograms available for review.

tPreoperative neurological instability as per selected criteria from Sundt et al: ${ }^{19}, 20$ progressing neurological deficit, or neurological deficit within one day prior to carotid endarterectomy.

¥High-risk preoperative medical conditions: unstable angina, myocardial infarction within three months prior to carotid endarterectomy, or uncontrolled heart failure.

$\mathrm{Cl}$ indicates confidence interval. 
TABLE 2-5. Significant risk factors for postoperative complications by univariate analysis

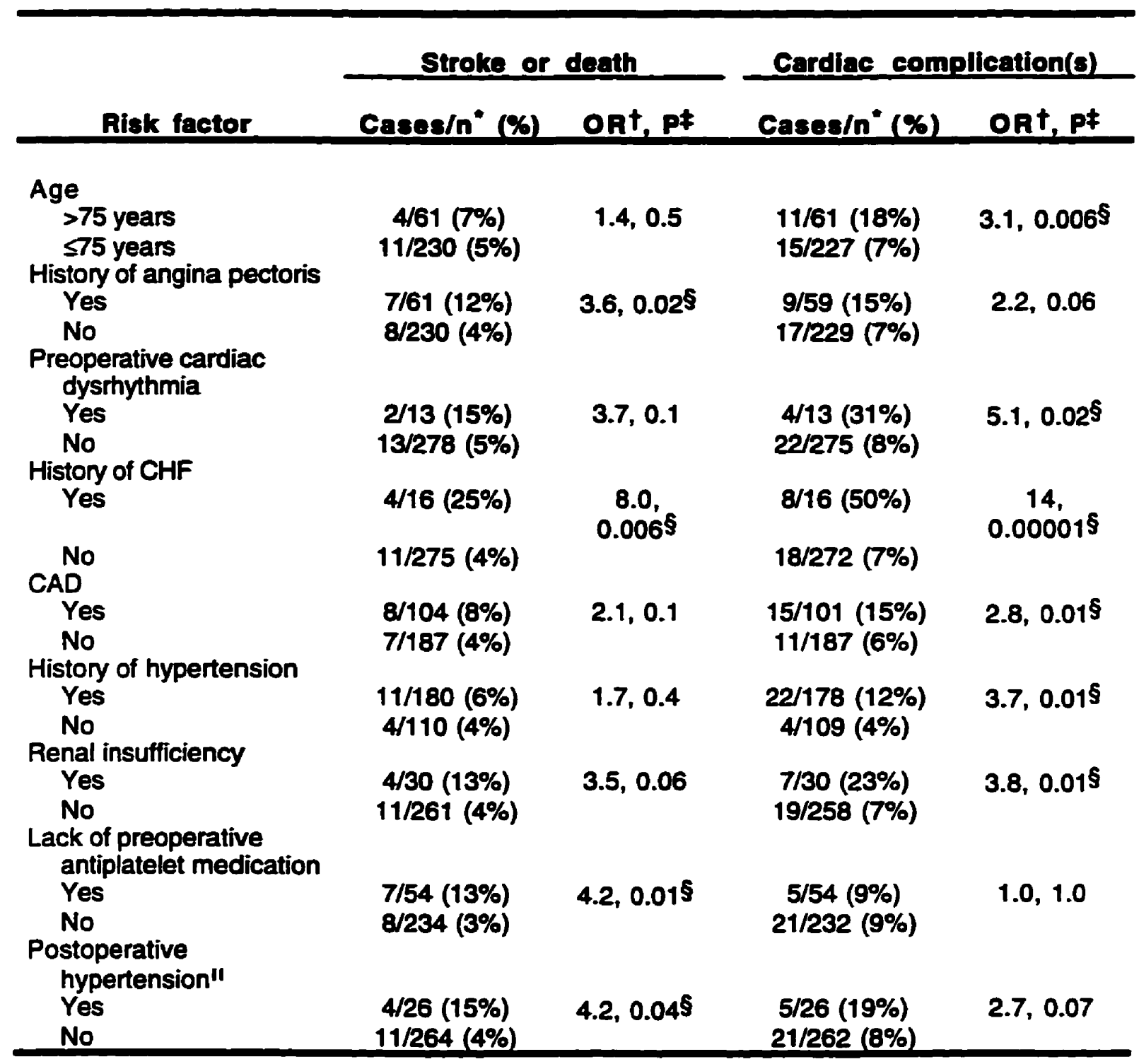

"Number of cases with complication, divided by total number of cases with or without risk factor.

TP value of Chi square or Fisher's exact test, (two-tailed).

FOdds ratio calculated for presence of risk factor associated with complication.

\$Statistically significant at $P$ value $\leq 0.05$.

"Defined as any episode of systolic blood pressure $>220 \mathrm{~mm} \mathrm{Hg}$ from arrival in the recovery room until the end of the first postoperative day.

CHF indicates congestive heart failure; CAD, coronary artery disease. 
TABLE 2-6. Independent preoperative risk factors for postoperative complications by multiple logistic regression analysis

Stroke or death

History of angina pectoris

1.9 (1.03 to 3.4)

History of CHF

2.6 (1.2 to 5.6)

Lack of preoperative antiplatelet

2.5 (1.4 to 4.5$)$

medication

Cardiac complication(s)

Age $>75$ years

1.8 (1.1 to 2.9$)$

History of CHF

4.1 (2.2 to 7.5$)$

$\mathrm{Cl}$ indicates confidence interval; $\mathrm{CHF}$, congestive heart failure. 
TABLE 2-7. Summary of selected randomized controlled trial results

\begin{tabular}{|c|c|c|c|c|c|}
\hline Trial & $\begin{array}{c}\text { Patient } \\
\text { population }\end{array}$ & $\begin{array}{l}\text { Outcome } \\
\text { event(s) }\end{array}$ & $\begin{array}{l}\text { Stroke or } \\
\text { death rate* }\end{array}$ & $\begin{array}{l}\text { NNTt, } \\
\text { study } \\
\text { period }\end{array}$ & $\begin{array}{l}\text { NNT } \neq \text { at } \\
1 \text { year, } \\
2 \text { years }\end{array}$ \\
\hline NASCET $^{9,53}$ & $\begin{array}{c}\text { Symp } \geq 70 \% \\
\text { stenoses }\end{array}$ & Ipsi stroke§ & $5.8 \%$ & 6,2 years & 10,6 \\
\hline $\mathrm{ECST}^{10,53}$ & $\begin{array}{c}\text { Symp } \geq 82 \% " \\
\text { stenoses }\end{array}$ & $\begin{array}{c}\text { lpsi stroke } \\
\text { lasting > } 7 \text { days } \$\end{array}$ & $7.5 \%$ & 6,3 years & 11,6 \\
\hline $\begin{array}{l}\text { VA Study - } \\
\text { symp }^{12}\end{array}$ & $\begin{array}{c}\text { Symp>50\% } \\
\text { stenoses }\end{array}$ & $\begin{array}{l}\text { Ipsi crescendo } \\
\text { TIA, stroke, or } \\
\text { retinal infarct\$ }\end{array}$ & $5.5 \%$ & 9,1 year & $9,7 \pi$ \\
\hline $\begin{array}{l}\text { VA Study - } \\
\text { asymp } 11\end{array}$ & $\begin{array}{c}\text { Asymp }>50 \% \\
\text { stenoses }\end{array}$ & $\begin{array}{c}\text { Ipsi TIA, TMB, or } \\
\text { stroke }\end{array}$ & $4.3 \%$ & 8,4 years & 20,11 \\
\hline $\operatorname{ACAS}^{13,51}$ & $\begin{array}{c}\text { Asymp } \geq 60 \% \\
\text { stenoses }\end{array}$ & Ipsi stroke§ & $1.2 \%$ & 17,5 years & $\begin{array}{c}\text { no benefit, } \\
67\end{array}$ \\
\hline
\end{tabular}

"Only strokes or deaths within $\mathbf{3 0}$ days of surgery considered; patients with complications due to angiography excluded.

tNumber (of patients) needed to treat with carotid endarterectomy to prevent one outcome over study period; calculated by the reciprocal of the absolute risk reduction as published in each respective trial.

FNNT at 1 and 2 years calculated from published Kaplan-Meier curves from referenced source(s); used here to roughly compare trial efficacies among the various studies.

SOutcome includes perioperative stroke or death within 30 days of surgery.

$182 \%$ ECST stenosis equivalent to $70 \%$ NASCET stenosis. ${ }^{53}$

INNT at 2 years unreliable since mean followup time was 1 year.

NASCET indicates North American Symptomatic Carotid Endarterectomy Trial; symp, symptomatic; ipsi, ipsilateral; ECST, European Carotid Stenosis Trial; VA, Veterans Affairs; TIA, transient ischemic attack; asymp, asymptomatic; TMB, transient monocular blindness; ACAS, Asymptomatic Carotid Atherosclerosis Study. 


\section{Bibliography}

1. Warlow C. Carotid endarterectomy: does it work? Stroke. 1984;15:1068-1076.

2. Barnett HJ, Plum F, Walton JN. Carotid endarterectomy - an expression of concern. Stroke. 1984;15:941-943.

3. Winslow CM, Solomon DH, Chassin MR, Kosecoff J, Merrick NJ, Brook RH. The appropriateness of carotid endarterectomy. NEJM. 1988;318:721-727.

4. Easton JD, Sherman DG. Stroke and mortality rate in carotid endarterectomy: 228 consecutive operations. Stroke. 1977;8:565-568.

5. Brott $T$, Thalinger $K$. The practice of carotid endarterectomy in a large metropolitan area. Stroke. 1984;15:950-955.

6. Brott TG, Labutta RJ, Kempczinski RF. Changing patterns in the practice of carotid endarterectomy in a large metropolitan area. JAMA. 1986;255:2609-2612.

7. Dyken ML, Pokras R. The performance of endarterectomy for disease of the extracranial arteries of the head. Stroke. 1984;15:948-950.

8. Fode NC, Sundt TM Jr, Robertson JT, Peerless SJ, Shields CB. Multicenter retrospective review of results and complications of carotid endarterectomy in 1981. Stroke. 1986;17:370-376.

9. North American Symptomatic Carotid Endarterectomy Trial Collaborators. Beneficial effect of carotid endarterectomy in symptomatic patients with high-grade carotid stenosis. NEJM. 1991;325:445-453.

10. European Carotid Surgery Trialists' Collaborative Group. MRC European Carotid Surgery Trial: interim results for symptomatic patients with severe (70-99\%) or with mild (0-29\%) carotid stenosis. Lancet. 1991;337:1235-1243. 
11. Hobson RW, Weiss DG, Fields WS, Goldstone J, Moore WS, Towne JB, Wright CB, The Veterans Affairs Cooperative Study Group. Efficacy of carotid endarterectomy for asymptomatic carotid stenosis. NEJM. 1993;328:221-227.

12. Mayberg MR, Wilson SE, Yatsu F, Weiss DG, Messina L, Hershey LA, Colling C, Eskridge J, Deykin D, Winn HR, Veterans Affairs Cooperative Studies Program 309 Trialist Group. Carotid endarterectomy and prevention of cerebral ischemia in symptomatic carotid stenosis. JAMA. 1991;266:3289-3294.

13. Executive Committee for the Asymptomatic Carotid Atherosclerosis Study. Endarterectomy for asymptomatic carotid artery stenosis. JAMA. 1995;273:14211428.

14. Gillum RF. Epidemiology of carotid endarterectomy and cerebral angiography in the United States. Stroke. 1995;26:1724-1728.

15. Fox AJ. How to measure carotid stenosis. Radiology. 1993;186:316-318.

16. North American Symptomatic Carotid Endarterectomy Trial (NASCET) Steering Committee. North American Symptomatic Carotid Endarterectomy Trial. Methods, patient characteristics, and progress. Stroke. 1991;22:711-720.

17. Streifler JY, Eliasziw M, Fox AJ, Benavente OR, Hachinski VC, Ferguson GG, Barnett HJ. Angiographic detection of carotid plaque ulceration. Comparison with surgical observations in a multicenter study. North American Symptomatic Carotid Endarterectomy Trial. Stroke. 1994;25:1130-1132.

18. Moore WS, Barnett HJ, Beebe HG, Bernstein EF, Brener BJ, Brott T, Caplan LR, Day A, Goldstone J, Hobson RW 2nd, Kempczinski RF, Matchar DB, Mayberg MR, Nicolaides AN, Norris JW, Ricotta JJ, Robertson JT, Rutherford RB, Thomas D, Toole JF, Trout HH 3rd, Wiebers DO. Guidelines for carotid endarterectomy. A multidisciplinary consensus statement from the ad hoc Committee, American Heart Association. Stroke. 1995;26:188-201. 
19. Sundt TM, Sandok BA, Whisnant JP. Carotid endarterectomy. Complications and preoperative assessment of risk. Mayo Clin Proc. 1975;50:301-306.

20. McCrory DC, Goldstein LB, Samsa GP, Oddone EZ, Landsman PB, Moore WS, Matchar DB. Predicting complications of carotid endarterectomy. Stroke. 1993;24:1285-1291.

21. Merrick NJ, Brook RH, Fink A, Solomon DH. Use of carotid endarterectomy in five California Veterans Administration medical centers. JAMA. 1986;256:25312535.

22. Asaph JW, Janoff K, Wayson K, Kilberg L, Graham M. Carotid endarterectomy in a community hospital: a change in physicians' practice patterns. Am J Surg. 1991;161:616-618.

23. Wilterdink JL, Easton JD. Vascular event rates in patients with atherosclerotic cerebrovascular disease. Arch Neurol. 1992;49:857-863.

24. The European Carotid Surgery Trialists Collaborative Group. Risk of stroke in the distribution of an asymptomatic carotid artery. Lancet. 1995;345:209-212.

25. Anonymous. Clinical advisory: carotid endarterectomy for patients with asymptomatic internal carotid artery stenosis. Stroke. 1994;25:2523-2524.

26. Park RE, Fink A, Brook RH, Chassin MR, Kahn KL, Merrick NJ, Kosecoff J, Solomon DH. Physician ratings of appropriate indications for three procedures: theoretical indications vs indications used in practice. Am J Public Health. 1989;79:445-447.

27. McClellan M, Brook RH. Appropriateness of care. A comparison of global and outcome methods to set standards. Med Care. 1992;30:565-586.

28. Kahan JP, Park RE, Leape LL, Bernstein SJ, Hilborne LH, Parker L, Kamberg CJ, Ballard DJ, Brook RH. Variations by specialty in physician ratings of the appropriateness and necessity of indications for procedures. Med Care. 1996;34:512-523. 
29. Leape LL, Park RE, Kahan JP, Brook RH. Group judgments of appropriateness: the effect of panel composition. Qual Assur Health Care. 1992;4:151-159.

30. Eliasziw M, Smith RF, Singh N, Holdsworth DW, Fox AJ, Barnett HJ. Further comments on the measurement of carotid stenosis from angiograms. North American Symptomatic Carotid Endarterectomy Trial (NASCET) Group. Stroke. $1994 ; 25: 2445-2449$.

31. The CASANOVA Study Group. Carotid surgery versus medical therapy in asymptomatic carotid stenosis. Stroke. 1991;22:1229-1235.

32. Barnett HJM, Taylor DW. Clinical trials in stroke prevention - persisting uncertainties, firm answers. Neurology. 1993;43:2163-2166.

33. Blakeley DD, Oddone EZ, Hasselblad V, Simel DL, Matchar DB. Noninvasive carotid artery testing. A meta-analytic review. Ann Intern Med. 1995;122:360367.

34. Eliasziw M, Rankin RN, Fox AJ, Haynes RB, Barnett HJ. Accuracy and prognostic consequences of ultrasonography in identifying severe carotid artery stenosis. North American Symptomatic Carotid Endarterectomy Trial (NASCET) Group. Stroke. 1995;26:1747-1752.

35. Srinivasan J, Mayberg MR, Weiss DG, Eskridge J. Duplex accuracy compared with angiography in the Veterans Affairs Cooperative Studies Trial for symptomatic carotid stenosis. Neurosurgery. 1995;36:648-655.

36. Rothwell PM, Slattery J, Warlow CP. A systematic review of the risks of stroke and death due to endarterectomy for symptomatic carotid stenosis. Stroke. $1996 ; 27: 260-265$.

37. Rothwell PM, Slattery J, Warlow CP. A systematic comparison of the risks of stroke and death due to carotid endarterectomy for symptomatic and asymptomatic stenosis. Stroke. 1996;27:266-269. 
38. Plecha EJ, King TA, Pitluk HC, Rubin JR. Risk assessment in patients undergoing carotid endarterectomy. Cardiovasc Surg. 1993;1:30-32.

39. Goldstein LB, McCrory DC, Landsman PB, Samsa GP, Ancukiewicz M, Oddone EZ, Matchar DB. Multicenter review of preoperative risk factors for carotid endarterectomy in patients with ipsilateral symptoms. Stroke. 1994;25:1116-1121.

40. Sieber FE, Toung TJ, Diringer MN, Wang H, Long DM. Preoperative risks predict neurological outcome of carotid endarterectomy related stroke. Neurosurgery. 1992;30:847-854.

41. Steed DL, Peitzman AB, Grundy BL, Webster MW. Causes of stroke in carotid endarterectomy. Surgery. 1982;92:634-641.

42. Burke PA, Callow AD, O’Donnell TF Jr, Kelly JJ, Welch H. Prophylactic carotid endarterectomy for asymptomatic bruit. A look at cardiac risk. Arch Surg. $1982 ; 117: 1222-1227$.

43. Chimowitz MI, Weiss DG, Cohen SL, Starling MR, Hobson RW 2nd, Veterans Affairs Cooperative Study Group 167. Cardiac prognosis of patients with carotid stenosis and no history of coronary artery disease. Stroke. 1994;25:759-765.

44. Musser DJ, Nicholas GG, Reed JF 3rd. Death and adverse cardiac events after carotid endarterectomy. J Vasc Surg. 1994;19:615-622.

45. Urbinati S, Di Pasquale G, Andreoli A, Lusa AM, Ruffini M, Lanzino G, Pinelli G. Frequency and prognostic significance of silent coronary artery disease in patients with cerebral ischemia undergoing carotid endarterectomy. Am J Cardiol. 1992;69:1166-1170.

46. Yeager RA, Moneta GL, McConnell DB, Neuwelt EA, Taylor LM Jr, Porter JM. Analysis of risk factors for myocardial infarction following carotid endarterectomy. Arch Surg. 1989;124:1142-1145.

47. Rihal CS, Gersh BJ, Whisnant JP, Rooke TW, Sundt TM Jr, O'Fallon WM, Ballard DJ. Influence of coronary heart disease on morbidity and mortality after 
carotid endarterectomy: a population-based study in Olmsted County, Minnesota (1970-1988). J Am Coll Cardiol. 1992;19:1254-1260.

48. Mackey WC, O'Donnell TF Jr, Callow AD. Cardiac risk in patients undergoing carotid endarterectomy: impact on perioperative and long-term mortality. $J$ Vasc Surg. 1990;11:226-233.

49. Urbinati S, Di Pasquale G, Andreoli A, Lusa AM, Carini G, Grazi P, Labanti G, Passarelli P, Corbelli C, Pinelli G. Preoperative noninvasive coronary risk stratification in candidates for carotid endarterectomy. Stroke. 1994;25:20222027.

50. Wong JH, Findlay JM. Monitoring patients in the intensive care unit after carotid endarterectomy. Can J Surg. 1996;39:431-432. Letter.

51. Barnett HJ, Eliasziw M, Meldrum HE, Taylor DW. Do the facts and figures warrant a 10-fold increase in the performance of carotid endarterectomy on asymptomatic patients? Neurology. 1996;46:603-608.

52. Halliday AW, Thomas D, Mansfield A. The Asymptomatic Carotid Surgery Trial (ACST). Rationale and design. Steering Committee. Eur J Vasc Surg. 1994;8:703-710.

53. Barnett HJ, Warlow CP. Carotid endarterectomy and the measurement of stenosis. Stroke. 1993;24:1281-1284 (published erratum appears in Stroke 1994;25:758). 


\section{Chepter 3}

\section{HeMOdYNAMIC INSTABILITY After Garotid Endarterectomy: RisK FACTORS AND ASSOCIATIONS with Operative Complications}

A version of this chapter has been submitted for publication. Wong JH, Findlay JM, Suarez-AImazor ME, Hemodynamic instability after carotid endarterectomy: Risk factors and associations with operative complications. 


\section{Summary}

Objectrve To examine the incidences of hypertension, hypotension, and bradycardia following carotid endarterectomy (CEA) and identify any hemodynamic variables predictive of postoperative stroke or death, or cardiac complications.

Methods Retrospective population-based cohort study of 291 consecutive patients undergoing CEA using hospital chart review. Hemodynamic data collected from time of arrival in the recovery room until the end of the first postoperative day. Primary and secondary outcome events were stroke or death within $\mathbf{3 0}$ days of surgery, and any postoperative cardiac complication (angina, congestive heart failure, dysrhythmia, or myocardial infarction), respectively.

Results The incidences of postoperative hypertension (systolic blood pressure [sBP] $>220 \mathrm{~mm} \mathrm{Hg}$ ), hypotension (sBP $<90 \mathrm{~mm} \mathrm{Hg}$ ), and bradycardia (pulse $<60$ beats per minute) were 9\% (26/290), 12\% (36/290), and 55\% (159/290), respectively. The stroke or death rate was 5.2\% (15/291). Postoperative hypertension was associated significantly with stroke or death $(\mathrm{P}=0.04)$ and by a statistical trend with cardiac complications $(\mathrm{P}=0.07)$. Independent preoperative risk factors for postoperative hypertension by multivariate analysis were angiographic intracranial carotid stenosis $>50 \%$, cardiac dysrhythmia, preoperative $\mathrm{SBP}>160 \mathrm{~mm} \mathrm{Hg}$, neurological instability, and renal insufficiency. Postoperative hypotension and bradycardia did not correlate with primary or secondary outcomes.

Conclusion Hemodynamic instability was commonly observed after CEA but only postoperative hypertension was associated with stroke or death, and possibly with cardiac complications. Patients undergoing CEA, especially those at risk for postoperative 
hypertension, may best be monitored in settings suited to the expeditious management of neurological and cardiovascular emergencies.

Some degree of hemodynamic instability, defined as the occurrence of hypertension, hypotension, or bradycardia, commonly develops after carotid endarterectomy (CEA). ${ }^{1-3}$ Postoperative arterial hypertension may be due to dysfunction of adventitial baroreceptors in the endarterectomized carotid artery segment, although metabolic factors such as renin and vasopressin have also been implicated. ${ }^{4-6}$ Bradycardia, sometimes associated with hypotension, also occurs frequently in the early postoperative period, and is thought to be related to increased activity from the carotid sinus nerve or carotid baroreceptors after removal of the atheromatous plaque. ${ }^{7,8}$

These postoperative cardiovascular fluctuations are usually transient but their clinical significance is unclear. Hemodynamic instability after CEA has been linked to surgical morbidity and mortality, and especially to stroke and cardiac complications. 3, 9-16 However, prior studies tended to examine hypertension alone as a hemodynamic risk factor, were frequently restricted by limited sample sizes, and did not use multivariate statistical techniques in assessing associations with outcomes. In this study, our goal was to determine the incidences of postoperative hypertension, hypotension, and bradycardia after CEA in our patient population undergoing this operation, and to examine any associations with neurological and cardiac complications and death. As well, we wished to identify any preoperative risk factors predictive of clinically significant hemodynamic problems. 


\section{Pationts and Mothods}

We performed a population-based, retrospective cohort study of all patients who underwent CEA within the city of Edmonton, Alberta from April 1, 1994 to September 30, 1995. Clinical and radiological information was collected primarily by examination of inhospital medical records, and, if necessary, supplemented through review of available office records of individual surgeons. For this study, hypertension was defined as any episode of systolic blood pressure (sBP) greater than $220 \mathrm{~mm} \mathrm{Hg}$, hypotension as any sBP less than $90 \mathrm{~mm} \mathrm{Hg}$, and bradycardia as any pulse less than 60 beats per minute, occurring anytime from patient arrival in the recovery room until the end of the first postoperative day. Blood pressure values were obtained from either cuff or arterial line monitoring although preference was given to the latter if available. A carotid plaque was considered symptomatic if there was a documented history of prior retinal or cerebral ischemia referable to the stenotic lesion, i.e. ipsilateral transient ischemic attack, stroke, amaurosis fugax, or retinal infarction. Radiological information was obtained from ultrasonography reports which were available for review in $88 \%$ of patients who underwent this diagnostic procedure preoperatively (219/248). All patients underwent angiography prior to CEA and 97\% of these films (281/291) were reviewed by the investigators (J.H.W. and J.M.F.) who were blinded to patient identity and reported findings.

Patient follow-up was conducted through telephone interview of patients or their families, and/or survey of ambulatory care records from the operating surgeons' offices. Additional follow-up concerning death after hospital discharge was obtained through database searches of the provincial government mortality registry using linkage analyses with name and birth date.

A primary outcome event was defined as any stroke or death occurring within $\mathbf{3 0}$ days of CEA. Any hemispheric neurological deficit lasting greater than 24 hours was classified as a stroke, with a major stroke being defined as one producing a functional 
deficit. For example, a patient rendered incapable of independent activities of daily living or requiring further rehabilitation was classified as having a major deficit, while mild weakness in a patient otherwise capable of independent ambulation and returning home upon discharge was classified as a minor stroke. The degree of clinical recovery after hospital discharge was not assessed. A secondary outcome event was the development of at least one postoperative cardiac complication in hospital, specifically angina, congestive heart failure (CHF), dysrhythmia, or myocardial infarction.

Data was collected using a computer database (FileMaker Pro 2.1, Claris Corporation, Santa Barbara, CA, USA) and analyzed with statistical software (SPSS 6.1, SPSS Incorporated, Chicago, IL, USA). Means were expressed \pm standard error of the mean. Univariate testing utilized Chi-square and Fisher's exact tests for comparison of proportions. Measures of association between risk factors and outcome events were expressed as odds ratios (ORs) with $95 \%$ confidence intervals. Level of significance was set at $\mathrm{P} \leq 0.05$ and all tests were two-tailed. The associations between risk factors and outcome events were also evaluated by multivariate analysis using logistic regression models. Dependent variables were the dichotomous outcomes of stroke or death, and cardiac complications. Independent variables used in these models were selected from those listed in table 3-3. A stepwise procedure was used to include variables in the model using a probability of 0.05 for variable inclusion and 0.10 for exclusion.

\section{Results}

Two-hundred and ninety one cases of CEA were performed in 265 patients by nine surgeons from the neurosurgical, general surgery, and vascular surgery services at four centres, two of which were tertiary-care teaching hospitals. The patient mean age was $67.8 \pm 0.5$ years and $58 \%$ were male (170/291). Patient characteristics are summarized in table 3-1. 
Forty percent of operations (118/291) were for asymptomatic stenosis, and the remainder were for symptomatic disease. All cases were performed under general anesthesia. Intraoperative shunting and carotid patching were used in 41\% (119/291) and $14 \%(42 / 291)$ of cases, respectively. The cross-clamp time for the majority of patients could not be assessed due to inadequate documentation in the hospital record.

There were two levels of postoperative care available to our patient population: the surgical ward and the intensive care unit (ICU). Standard ICU care included continuous blood pressure measurements by arterial line and cardiac rhythm monitoring. One hundred and eighteen patients (41\%) were admitted to the ICU as a matter of pre-arranged, routine postoperative care due to surgeon preference. Those 165 patients discharged to the surgical ward from the recovery room (57\%) had arterial lines removed prior to transfer, and were observed by frequent nursing assessments of neurological function and vital signs without electrocardiographic monitoring. Eight patients (3\%) were originally assigned to the surgical ward, but were subsequently admitted urgently to the ICU as a result of unexpected complications.

Hemodynamic data was available in all but one patient due to missing hospital documentation. The incidences of postoperative hypertension, hypotension, and bradycardia were 9\% (26/290), 12\% (36/290), and 55\% (159/290), respectively, as shown in table 3-2. At least one of these hemodynamic events occurred in $62 \%(181 / 290)$ of patients. In the total patient population, oral antihypertensive agents were used in 117 cases (40\%) and parenteral antihypertensive agents in 36 cases (12\%), during the postoperative interval up until the end of the first day after CEA. For patients with low blood pressure values requiring intervention, six patients received parenteral pressor agents alone (2\%), 22 were given intravenous fluid boluses (8\%), and six were given both (2\%). Atropine was used in 18 patients (6\%).

The 30 day stroke or death rate was $5.2 \%$ (15/291). Six major strokes and five minor strokes occurred postoperatively, all except one developing in hospital. Of the 11 
strokes, three were immediately apparent upon patient awakening from anesthesia, three developed within one hour of surgery, three occurred after the first hour but within 24 hours of CEA, and two developed after 24 hours postoperatively. Of the four deaths in this series occurring within 30 days of CEA, two were due to myocardial infarction, one was due to ischemic bowel secondary to cardiovascular causes, and the last was due to interstitial pneumonitis developing after discharge from hospital. Overall, 26 patients (9\%) developed at least one postoperative cardiac complication. Angina occurred in four patients (1\%), congestive heart failure developed in 17 patients $(6 \%)$, myocardial infarction developed in five patients (3\%), and a new cardiac dysrhythmia occurred in ten patients (3\%).

Patients were stratified according to their site of pre-arranged postoperative care; routine ICU monitoring was defined as postoperative care in an ICU setting that had been planned preoperatively. There were no significant differences between the 118 patients routinely monitored in the ICU, versus the 173 patients cared for on the surgical ward (or transferred to the ICU due to unexpected complications) with respect to the development of hypertension or bradycardia. However, hypotension was less often observed in those routinely monitored in the ICU as compared to those without such care (7\% versus $16 \%$, respectively, $[\mathrm{P}=0.02])$; this disparity could not be explained by variation in pressor or intravenous bolus use. Those patients with pre-arranged ICU care, as compared to those without, were at less risk to suffer a postoperative stroke or death (4\% versus $6 \%$, respectively) and were more likely to develop a cardiac complication ( $12 \%$ versus $7 \%$ ), respectively), although these differences did not reach statistical significance.

Postoperative hypertension was found to be significantly associated with stroke or death by univariate analysis, $(P=0.04$, Fisher's exact test). Using a logistic regression model with entry of multiple variables (including postoperative hypertension), it was found that a history of angina, a history of CHF, and lack of preoperative antiplatelet medication use were the only independent risk factors for stroke or death. With respect to cardiac 
complications, a nonsignificant statistical trend towards an association with postoperative hypertension was noted ( $P=0.07$, Fisher's exact test). Neither stroke or death, nor cardiac complications were found to be significantly associated with hypotension ( $P=0.41$ and 0.34 , respectively, Fisher's exact test), or bradycardia ( $P=0.23$ and 0.87 , respectively, Chi square test).

Since postoperative hypertension was a significant risk factor for stroke or death (and possibly for cardiac complications) by univariate analysis, preoperative risk factors predictive of postoperative hypertension were investigated by both univariate and multivariate techniques. These results are summarized in tables 3-3 and 3-4. Independent preoperative risk factors for postoperative hypertension derived by multiple logistic regression analysis were a sBP greater than $160 \mathrm{~mm} \mathrm{Hg}$ prior to surgery, a history of cardiac dysrhythmia, renal insufficiency, neurological instability as based upon selected criteria described by Sundt and colleagues, ${ }^{17,} 18$ and angiographic intracranial carotid stenosis greater than $50 \%$ (as measured by comparing the stenotic region with the distal normal arterial segment).

\section{Discussion}

It is unclear from the literature as to whether hemodynamic instability after CEA is benign or dangerous. Case studies have implicated hypertension as a potential cause of postoperative stroke, ${ }^{12}$ intracranial hemorrhage, ${ }^{13-15}$ and encephalopathy. ${ }^{16}$ Some studies have been unable to demonstrate an association between postoperative hypertension and stroke, ${ }^{19}, 20$ but these may have been limited by insufficient sample size and the fact that complication rates were relatively low. The present study, using one of the largest patient cohorts to examine this issue, found that postoperative systolic hypertension greater than $220 \mathrm{~mm} \mathrm{Hg}$ was significantly associated with stroke or death by univariate analysis, but was not associated by multiple regression thus indicating its linkage with other independent 
preoperative risk factors. This finding is in agreement with previous large cohort studies. Asiddao and colleagues found in a retrospective cohort study of 166 CEA patients that a sustained postoperative $s B P \geq 200 \mathrm{~mm} \mathrm{Hg}$ or diastolic pressure $\geq 110 \mathrm{~mm} \mathrm{Hg}$ that required pharmacologic intervention, was significantly associated with the combined events of transient ischemic attack and stroke. ${ }^{9}$ Hans and colleagues similarly found that postoperative hypertension (defined as a $\mathrm{sBP}>180 \mathrm{~mm} \mathrm{Hg}$ or $>35 \mathrm{~mm} \mathrm{Hg}$ rise above baseline, a diastolic blood pressure $>100 \mathrm{~mm} \mathrm{Hg}$ or $>20 \mathrm{~mm} \mathrm{Hg}$ rise above baseline, or any blood pressure requiring parenteral antihypertensive agents) was linked to the development of a postoperative neurological deficit. ${ }^{10}$ Towne and Bernhard determined that of 253 cases of CEA, 19\% developed hypertension (defined as a sustained sBP $>200 \mathrm{~mm}$ Hg requiring pharmacologic control), which was also associated with postoperative stroke or death. ${ }^{11}$

Of note is that the definition of hypertension differs with the various studies mentioned and may influence the results obtained; the choice of a sBP greater than $220 \mathrm{~mm}$ $\mathrm{Hg}$ in the present study was based upon the suspicion that hypertension of this severity could potentially contribute to cerebral hyperperfusion, weaken the arteriotomy site, or impair cardiac function, and was therefore clinically important.

Whether hypertension caused stroke or death or represented an epiphenomenon of cerebral ischemia could not be determined by this study. Of the four patients with postoperative hypertension who suffered a stroke or death in this series, hypertension preceded the clinical onset of neurological deficit in one case, developed after stroke presentation in another, and was coincidental with stroke immediately upon recovery from anesthesia in two patients. Our study did not investigate the influence of intraoperative blood pressure fluctuations since these were felt to be probably related to iatrogenic and pharmacologic causes rather than represent spontaneous phenomena, and we could not assess any hemodynamic lability during patient transit to the recovery room. Also, although severe hypertension is frequently assumed to be detrimental to the postoperative patient, it 
remains unknown whether its avoidance or treatment actually changes complications rates. Our study population was comprised of patients who were variably monitored and treated for hemodynamic problems, usually depending upon the discretion of the individual surgeon and the degree of postoperative monitoring available (i.e. ICU versus surgical ward). These problems highlight the limits of a retrospective and observational study design. Definitive answers to these important issues would require a prospective controlled trial of CEA patients who develop postoperative hypertension who are then randomized to treatment or observation groups.

The present study found that $9 \%$ of patients developed at least one cardiac complication, which was associated with postoperative hypertension by only a statistical trend $(\mathrm{P}=0.07$, Fisher's exact test). However, clinical considerations should be balanced against the lack of statistical significance in this instance, since the impact of severe hypertension in a population known to harbor both symptomatic and occult coronary artery disease is likely to be important. ${ }^{21-28}$ It is probably best to strictly avoid severe hypertension in CEA patients.

Bradycardia developed in over half of our patient population but only $6 \%$ received atropine. This study was unable to demonstrate an association of bradycardia with stroke or death or cardiac complications, suggesting that this phenomenon is relatively benign. This finding agrees with the work of Margulies and coworkers, who in a retrospective cohort study, found bradycardia to occur in $49 \%$ of 233 CEA cases monitored in an ICU, and felt bradycardia was harmless. ${ }^{29}$ Our study also did not find a link between hypotension with primary or secondary outcome events, in accord with previous studies that have been unable to correlate hypotension with the development of postoperative neurological deficits. 1,9 We could not account for the fact that hypotension occurred more frequently among those monitored on the surgical ward; possibly those patients constantly monitored in an ICU by arterial line had their rate of intravenous fluids adjusted upwards as needed but short of receiving a bolus. 
Previous studies identifying risk factors for the development of hypertension after CEA are uncommon, and used only univariate statistical techniques in their analyses.9.11. 20 Towne and Bernhard found preoperative hypertension to be associated with postoperative hypertension. " Similarly, Assidao and coworkers determined preoperative hypertension and peripheral vascular disease to be significant risk factors for hypertension following surgery. ${ }^{9}$ More recently, Benzel and colleagues identified preoperative hypertension, age greater than 65 years, black race, and intraoperative shunting as variables associated with postoperative hypertension. ${ }^{20}$ Using multiple logistic regression analysis, the present study found that a SBP greater than $160 \mathrm{~mm} \mathrm{Hg}$ before surgery, angiographic intracranial carotid stenosis, renal insufficiency, neurological instability, and a cardiac dysrhythmia were independent preoperative risk factors predictive of hypertension after CEA. However, a prognostic model for postoperative hypertension based upon these risk factors would need to be validated in an external data set prior to clinical application. Since hypotension and bradycardia were not found to be significantly related to surgical complications, associated risk factors were not investigated.

Given the low morbidity and mortality of modern CEA and concerns over cost containment, it has been recently proposed in a number of case series that most patients may be routinely and safely cared for outside of the ICU setting after CEA. ${ }^{30-37}$ Using scoring systems of illness severity and ICU care, O'Brien and Ricotta reported that only $18 \%$ of patients required ICU services as determined in a retrospective case series of 73 patients at one university hospital. ${ }^{32}$ Hoyle and colleagues found that in a multi-surgeon retrospective review of 384 cerebral revascularization procedures, 327 of which were CEAs, hospital costs were reduced $29 \%$ by combining selective ICU admission with case management protocols. ${ }^{38}$ In a case series of 126 CEA patients, McConnell and colleagues determined that $37 \%$ required active ICU care, and although they were unable to predict preoperatively which of these patients needed ICU care, proposed that a trial observation period in the recovery room allowed reliable recognition of ICU necessity prior to ward 
transfer. ${ }^{30}$ However, although other case series similarly have described the "selective" ICU admission of patients based upon their immediate postoperative course, $31,32,34$ these admissions could be considered in fact mandatory since these patients have already developed urgent problems requiring intensive care. A properly validated means of preoperatively identifying high-risk patients who need intensive care after CEA, has yet to be developed.

It remains unproven in a prospective, controlled study that general ward care after CEA is as safe as monitoring in an intensive care or close-monitoring unit. The high incidence of hemodynamic instability, the significant association of postoperative hypertension with stroke or death, and the possible link between hypertension and cardiac complications determined in the present study, raises the question of where we should care for patients following CEA. In this study, a lower rate of stroke or death was found in those patients routinely cared for in the ICU as compared to patients managed on the ward (4\% versus $6 \%$, respectively). However, this difference was not statistically significant or the result of a random allocation of patients to either postoperative setting. It is possible that the patients in our series with pre-arranged postoperative care in the ICU were a selected group, judged to be at higher operative risk with greater comorbidity. We did find that compared to ward-managed patients, significantly more of those monitored in the ICU had undergone a prior cardiac procedure or had suffered a preoperative dysthythmia $(P=0.04$ and 0.006 , respectively, Chi square test). This observation may explain the higher incidence of cardiac complications detected in the "routine ICU" group, along with an increased recognition of dysrhythmias resulting from continuous electrocardiographic monitoring. However, our study was not designed to evaluate any relative benefits of ICU versus ward care. The possible value of closely monitoring postoperative CEA patients can only be properly assessed in a randomized, controlled trial.

Future evidence may clarify what constitutes an acceptable and safe level of care after CEA. Until then, given the probability that postoperative ICU care may facilitate the 
recognition (and possibly reduce the severity) of complications when they occur, it is the preference of the neurosurgeons in our city to monitor CEA patients in a surgical ICU with constant blood pressure and electrocardiographic monitoring for approximately 24 hours following surgery. Rather than target the "luxury" of ICU use, it remains the philosophy of the regional neurosurgical staff to seek other avenues of lowering healthcare costs related to CEA that will not potentially sacrifice patient safety.

In summary, postoperative hemodynamic instability after CEA was common in our patient population but only systolic hypertension $>220 \mathrm{~mm} \mathrm{Hg}$ was associated with stroke or death and possibly with cardiac complications by univariate analysis. Independent preoperative risk factors for postoperative hypertension derived by multiple logistic regression techniques were a sBP greater than $160 \mathrm{~mm} \mathrm{Hg}$ prior to operation, angiographic intracranial carotid stenosis greater than 50\%, renal insufficiency, neurological instability, and a cardiac dysrhythmia. Until issues over the clinical significance of hemodynamic instability are resolved, it may be most appropriate to monitor CEA patients, especially those at risk for postoperative hypertension, in settings suited to the expeditious management of neurological and cardiovascular emergencies. 


\section{Tables}

TABLE 3-1. Frequency of selected patient characteristics

\begin{tabular}{lc}
\hline \multicolumn{1}{c}{ Characteristic } & Number of cases $(n=291)$ \\
\hline Age >75 years & $61(21 \%)$ \\
Angina pectoris & $61(21 \%)$ \\
Prior CABG or coronary angioplasty & $46(16 \%)$ \\
CAD & $104(36 \%)$ \\
History of CHF & $16(6 \%)$ \\
COPD & $64(22 \%)$ \\
Diabetes mellitus & $68(23 \%)$ \\
Cardiac dysthythmia & $13(5 \%)$ \\
Current nicotine use & $99(34 \%)$ \\
History of hypertension & $180(62 \%)$ \\
Hyperlipidemia & $124(43 \%)$ \\
History of MI & $58(20 \%)$ \\
Claudication & $40(14 \%)$ \\
Valvular heart disease & $18(6 \%)$ \\
Renal insufficiency & $30(10 \%)$ \\
Prior vascular surgery & $92(32 \%)$ \\
\hline
\end{tabular}

CABG indicates coronary artery bypass grafting; CAD, coronary artery disease; CHF, congestive heart failure; COPD, chronic obstructive pulmonary disease; MI, myocardial infarction. 
TABLE 3-2. Hemodynamic instability: Incidence and associations with complications

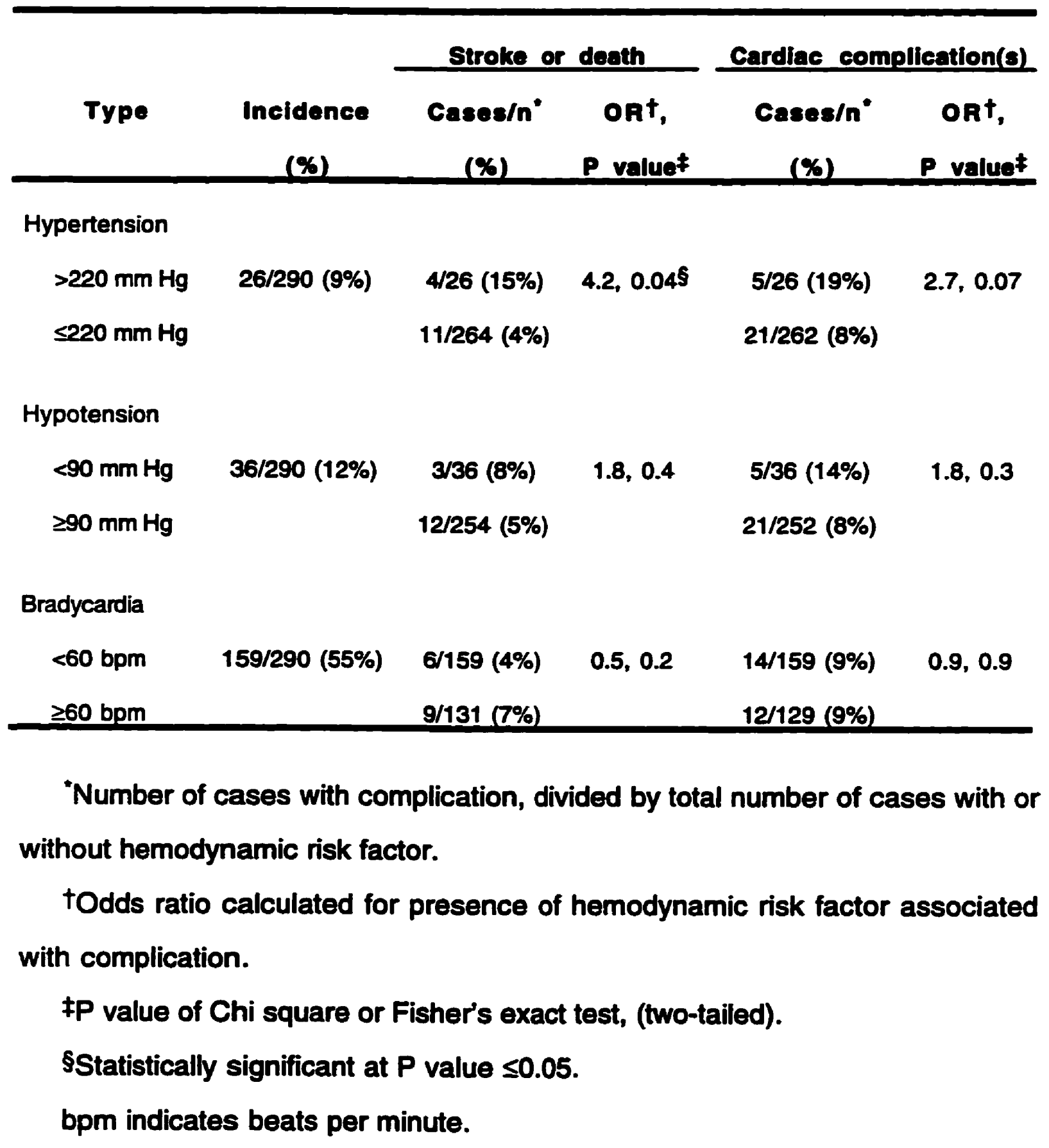


TABLE 3-3. Potential risk factors for postoperative hypertension by univariate analysis

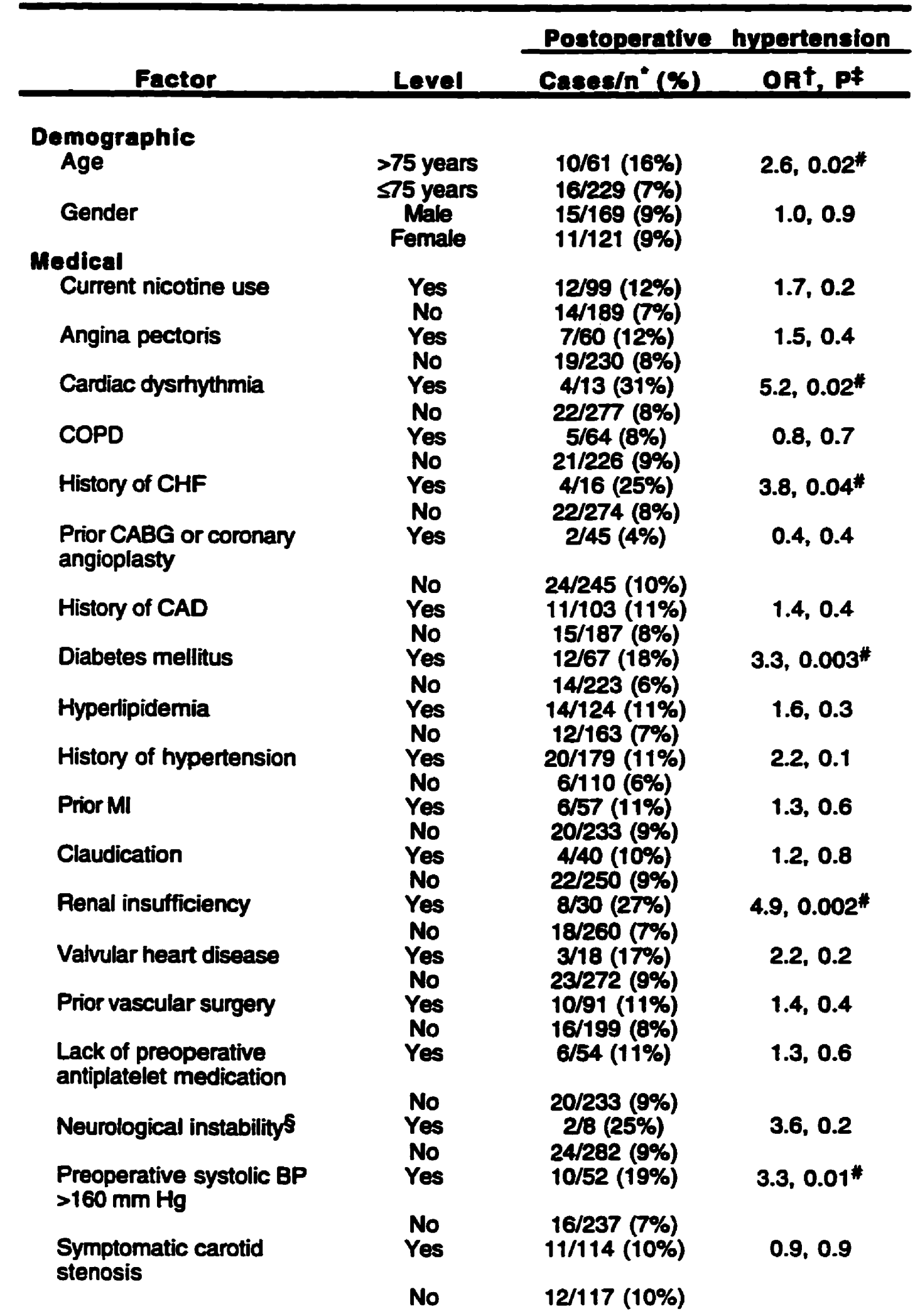


TABLE 3-3 continued.

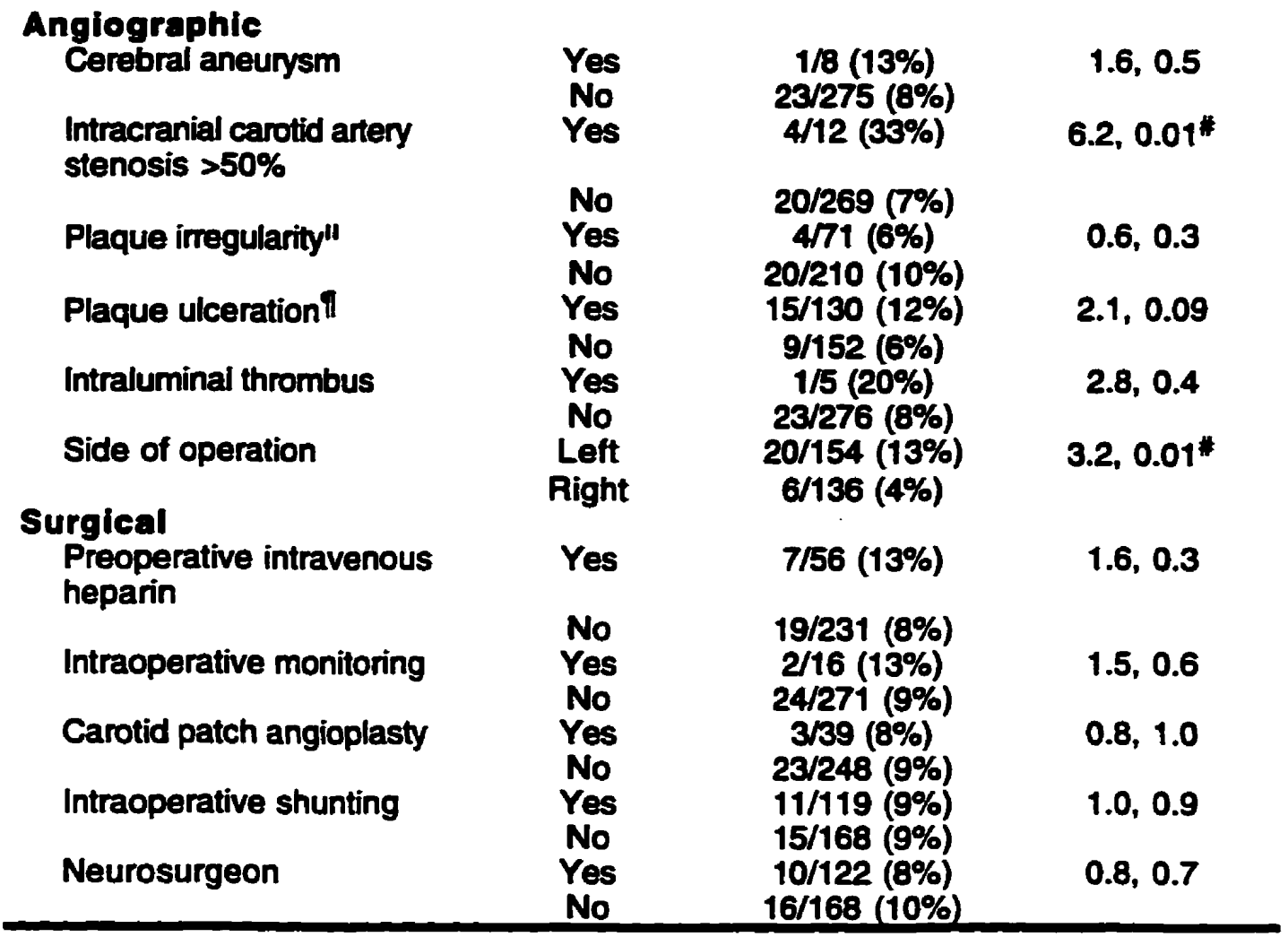

"Number of cases with postoperative hypertension, divided by total number of cases with or without factor.

tOdds ratio calculated for presence of risk factor associated with postoperative hypertension.

‡P value of Chi square or Fisher's exact test, (two-tailed).

\$Neurological instability as per selected criteria from Sundt et al: ${ }^{17,} 18$ progressing neurological deficit, or neurological deficit within one day of carotid endarterectomy.

"Plaque irregularity defined as the angiographic presence of vessel wall irregularity or multiple small craters. ${ }^{39}$

IPlaque ulceration defined as the angiographic presence of a crater penetrating into a stenotic plaque as seen in profile, or a double density when viewed "en face". 39

\#Statistically significant at $P$ value $\leq 0.05$.

COPD indicates chronic obstructive pulmonary disease; CHF, congestive heart failure; CABG, coronary artery bypass grafting; CAD, coronary artery disease; MI, myocardial infarction; BP, blood pressure. 
TABLE 3-4. Independent preoperative risk factors for postoperative hypertension by multivariate analysis

\begin{tabular}{ll}
\hline \multicolumn{1}{c}{ Risk Factor } & Odds Ratio (95\% C) \\
\hline Cardiac dysithythmia & $2.4(1.1$ to 5.2$)$ \\
Renal insufficiency & $2.0(1.2$ to 3.5$)$ \\
Preoperative systolic BP $>160 \mathrm{~mm} \mathrm{Hg}$ & $2.0(1.2$ to 3.3$)$ \\
Neurologically unstable* & $2.9(1.2$ to 6.9$)$ \\
Angiographic intracranial carotid stenosis $>50 \%$ & $3.4(1.7$ to 6.9$)$ \\
\hline
\end{tabular}

"Neurological instability as per selected criteria from Sundt et al:17, 18 progressing neurological deficit, or neurological deficit within one day of carotid endarterectomy.

$\mathrm{Cl}$ indicates confidence interval; BP, blood pressure. 


\section{Bibliography}

1. Bove EL, Fry WJ, Gross WS, Stanley JC. Hypotension and hypertension as consequences of baroreceptor dysfunction following carotid endarterectomy. Surgery. 1979;85:633-637.

2. Davies MJ, Cronin KD. Post carotid endarterectomy hypertension. Anaesth Intensive Care. 1980;8:190-194.

3. Skudlarick JL, Mooring SL. Systolic hypertension and complications of carotid endarterectomy. South Med J. 1982;75:1563-1565, 1567.

4. Smith BL. Hypertension following carotid endarterectomy: the role of cerebral renin production. $J$ Vasc Surg. 1984;1:623-627.

5. Lilly MP, Brunner MJ, Wehberg KE, Rudolphi DM, Queral LA. Jugular venous vasopressin increases during carotid endarterectomy after cerebral reperfusion. $J$ Vasc Surg. 1992;16:1-9.

6. Holton P, Wood JB. The effects of bilateral removal of the carotid bodies and denervation of the carotid sinuses in two human subjects. $J$ Physiol (Lond). 1965;181:365-378.

7. Angell-James JE, Lumley JS. The effects of carotid endarterectomy on the mechanical properties of the carotid sinus and carotid sinus nerve activity in atherosclerotic patients. Br J Surg. 1974;61:805-810.

8. Tarlov E, Schmidek H, Scott RM, Wepsic JG, Ojemann RG. Reflex hypotension following carotid endarterectomy: mechanism and management. $J$ Neurosurg. 1973;39:323-327.

9. Asiddao CB, Donegan JH, Whitesell RC, Kalbfleisch JH. Factors associated with perioperative complications during carotid endarterectomy. Anesth Analg. 1982;61:631-637. 
10. Hans SS, Glover JL. The relationship of cardiac and neurological complications to blood pressure changes following carotid endarterectomy. Am Surg. 1995;61:356359.

11. Towne JB, Bernhard VM. The relationship of postoperative hypertension to complications following carotid endarterectomy. Surgery. 1980;88:575-580.

12. Lehv MS, Salzman EW, Silen W. Hypertension complicating carotid endarterectomy. Stroke. 1970;1:307-313.

13. Bernstein M, Fleming JF, Deck JH. Cerebral hyperperfusion after carotid endarterectomy: a cause of cerebral hemorrhage. Neurosurgery. 1984;15:50-56.

14. Caplan LR, Skillman J, Ojemann R, Fields WS. Intracerebral hemorrhage following carotid endarterectomy: a hypertensive complication? Stroke. $1978 ; 9: 457-460$

15. Schroeder T, Sillesen H, Sorensen O, Engell HC. Cerebral hyperperfusion following carotid endarterectomy. J Neurosurg. 1987;66:824-829.

16. Ille O, Woimant F, Pruna A, Corabianu O, Idatte JM, Haguenau M. Hypertensive encephalopathy after bilateral carotid endarterectomy. Stroke. 1995;26:488-491.

17. McCrory DC, Goldstein LB, Samsa GP, Oddone EZ, Landsman PB, Moore WS, Matchar DB. Predicting complications of carotid endarterectomy. Stroke. $1993 ; 24: 1285-1291$.

18. Sundt TM, Sandok BA, Whisnant JP. Carotid endarterectomy. Complications and preoperative assessment of risk. Mayo Clin Proc. 1975;50:301-306.

19. Satiani B, Vasko JS, Evans WE. Hypertension following carotid endarterectomy. Surg Neurol. 1979;11:357-359.

20. Benzel EC, Hoppens KD. Factors associated with postoperative hypertension complicating carotid endarterectomy. Acta Neurochir(Wien). 1991;112:8-12. 
21. Chimowitz MI, Weiss DG, Cohen SL, Starling MR, Hobson RW 2nd, Veterans Affairs Cooperative Study Group 167. Cardiac prognosis of patients with carotid stenosis and no history of coronary artery disease. Stroke. 1994;25:759-765.

22. Burke PA, Callow AD, O’Donnell TF Jr, Kelly JJ, Welch H. Prophylactic carotid endarterectomy for asymptomatic bruit. A look at cardiac risk. Arch Surg. $1982 ; 117: 1222-1227$.

23. Musser DJ, Nicholas GG, Reed JF 3rd. Death and adverse cardiac events after carotid endarterectomy. J Vasc Surg. 1994;19:615-622.

24. Urbinati S, Di Pasquale G, Andreoli A, Lusa AM, Ruffini M, Lanzino G, Pinelli G. Frequency and prognostic significance of silent coronary artery disease in patients with cerebral ischemia undergoing carotid endarterectomy. Am J Cardiol. 1992;69:1166-1170.

25. Urbinati S, Di Pasquale G, Andreoli A, Lusa AM, Carini G, Grazi P, Labanti G, Passarelli P, Corbelli C, Pinelli G. Preoperative noninvasive coronary risk stratification in candidates for carotid endarterectomy. Stroke. 1994;25:2022-2027.

26. Yeager RA, Moneta GL, McConnell DB, Neuwelt EA, Taylor LM Jr, Porter JM. Analysis of risk factors for myocardial infarction following carotid endarterectomy. Arch Surg. 1989;124:1142-1145.

27. Rihal CS, Gersh BJ, Whisnant JP, Rooke TW, Sundt TM Jr, O'Fallon WM, Ballard DJ. Influence of coronary heart disease on morbidity and mortality after carotid endarterectomy: a population-based study in Olmsted County, Minnesota (1970-1988). J Am Coll Cardiol. 1992;19:1254-1260.

28. Mackey WC, O'Donnell TF Jr, Callow AD. Cardiac risk in patients undergoing carotid endarterectomy: impact on perioperative and long-term mortality. $J$ Vasc Surg. 1990;11:226-233.

29. Margulies DR, Hestrin MA, Lemus JF, Bjerke HS, Treiman RL, Shabot MM. Bradycardia following carotid endarterectomy. Am Surg. 1993;59:578-581. 
30. McConnell DB, Yeager RA, Moneta GL, Edwards JM, Deveney CW. "Just in time" decision making for ICU care after carotid endarterectomy. Am J Surg. 1996;171:502-504.

31. Lipsett PA, Tierney S, Gordon TA, Perler BA. Carotid endarterectomy - is intensive care unit care necessary? J Vasc Surg. 1994;20:403-409.

32. O'Brien MS, Ricotta JJ. Conserving resources after carotid endarterectomy: selective use of the intensive care unit. $J$ Vasc Surg. 1991;14:796-800.

33. Harbaugh KS, Harbaugh RE. Early discharge after carotid endarterectomy. Neurosurgery. 1995;37:219-225.

34. Collier PE. Carotid endarterectomy: a safe cost-efficient approach. $J$ Vasc Surg. 1992;16:926-929; discussion 930-923.

35. Kraiss LW, Kilberg L, Critch S, Johansen KH. Short-stay carotid endarterectomy is safe and cost-effective. Am J Surg. 1995;169:512-515.

36. Passerini L. Indications for intensive care unit care after carotid endarterectomy. Can J Surg. 1996;39:99-104.

37. Luna G, Adye B. Cost-effective carotid endarterectomy. Am J Surg. 1995;169:516-518.

38. Hoyle RM, Jenkins JM, Edwards WH Sr, Edwards WH Jr, Martin RS 3rd, Mulherin JL Jr. Case management in cerebral revascularization. J Vasc Surg. $1994 ; 20: 396-402$.

39. Streifler JY, Eliasziw M, Fox AJ, Benavente OR, Hachinski VC, Ferguson GG, Barnett HJ. Angiographic detection of carotid plaque ulceration. Comparison with surgical observations in a multicenter study. North American Symptomatic Carotid Endarterectomy Trial. Stroke. 1994;25:1130-1132. 


$$
=
$$




\section{Summary of Results}

The rate of uncertain and inappropriate surgeries was unacceptably high at in our region. Half of all patients underwent carotid endarterectomy (CEA) for uncertain indications. Inappropriate surgery was found in almost one in five patients and was related mainly to overestimation of mild and moderate asymptomatic carotid stenoses. The uniform use of a standard method of angiographic measurement of carotid stenosis may improve the rate of surgeries for appropriate indications. A substantial proportion of our study population was asymptomatic, and any marginal benefit of surgery for these patients was overshadowed by a significant risk of postoperative stroke or death. Preoperative risk factors were identified for stroke or death, and cardiac complications, which may offer an opportunity to reduce complication rates.

Hemodynamic instability after CEA was common in our patient population but only systolic hypertension after surgery was associated by univariate analysis with stroke or death and possibly with cardiac complications. Independent preoperative risk factors were identified for postoperative hypertension. Until the clinical significance of hemodynamic instability is defined, it may be most appropriate to monitor CEA patients, especially those at risk for postoperative hypertension, in settings suited to the expeditious management of neurological and cardiovascular emergencies.

\section{Potential Study Limitations}

This study was retrospective in design and may be subject to biases that are avoided in prospective studies. However, determining appropriateness prospectively with physician knowledge of an ongoing study would run the risk of altering their patterns of practice, thus lessening the validity and reliability of any findings. The population studied was that of patients with carotid stenosis who underwent surgery; it is important to note that this is a 
highly specific subgroup of the general population and the findings of this study should not be generalized to a broader group, i.e. all patients with carotid stenosis or all patients undergoing radiological investigations. Since the information source of this study was predominantly chart-based, the results may be influenced by paucity and inaccuracies of documentation. Potentially, an outcome event could be missed if a clinically insignificant event was not recorded, e.g. non-disabling minor stroke, which in this example would result in an underestimation of the true incidence of postoperative neurological complications. Our choice of the angiographic measurement method used in the North American Symptomatic Carotid Stenosis Trial may also be scrutinized. However, this method is well accepted in North American centers, has been used in several randomized trials, and was objectively applied in a blinded manner by the investigators. Our criteria of appropriateness were based upon published results from randomized trials widely available to clinicians; these criteria were applied to each patient in this study in conjunction with carefully remeasured carotid stenosis values.

\section{Study Implications}

The findings of this study suggest significant misuse of healthcare resources. Although there are many factors potentially influencing surgical patterns of practice, our study suggests that radiologic inaccuracy, especially angiographic, may play a significant role in the inappropriate use of CEA. Also, if the plausible assumption is made that our study findings are generalizable outside of our region, this study suggests that scientific evidence from well-performed research studies may not be reflected in routine surgical practice in the community. Local complication rates should be determined by independent audit. Our finding of an unacceptably high risk of postoperative stroke or death for asymptomatic patients suggests curtailing the use of this procedure for this patient group until the complication rate can be controlled. The identification of the high-risk patient 
through analysis of the risk factors determined in this study may allow reduction of neurological, cardiac, and hemodynamic complications. The significant frequency of hemodynamic problems after surgery, which may be associated with major operative complications, suggests that care of the postoperative patient should be focused upon close or intensive monitoring with ready access to vasoactive medications.

These findings emphasize the importance of the regional audit in identifying healthcare concerns on a local level. Addressing and correcting these problems will allow efficient use of increasingly scarce healthcare resources while maximizing safety for patients undergoing CEA. 